\title{
Essentialist Beliefs About Bodily Transplants in the United States and India
}

\author{
Meredith Meyer, ${ }^{\mathrm{a}}$ Sarah-Jane Leslie, ${ }^{\mathrm{b}}$ Susan A. Gelman, ${ }^{\mathrm{a}}$ Sarah M. Stilwell ${ }^{\mathrm{a}}$ \\ a Department of Psychology, University of Michigan \\ ${ }^{\mathrm{b}}$ Department of Philosophy, Princeton University
}

Received 28 November 2011; received in revised form 10 May 2012; accepted 20 June 2012

\begin{abstract}
Psychological essentialism is the belief that some internal, unseen essence or force determines the common outward appearances and behaviors of category members. We investigated whether reasoning about transplants of bodily elements showed evidence of essentialist thinking. Both Americans and Indians endorsed the possibility of transplants conferring donors' personality, behavior, and luck on recipients, consistent with essentialism. Respondents also endorsed essentialist effects even when denying that transplants would change a recipient's category membership (e.g., predicting that a recipient of a pig's heart would act more pig-like but denying that the recipient would become a pig). This finding runs counter to predictions from the strongest version of the "minimalist" position (Strevens, 2000), an alternative to essentialism. Finally, studies asking about a broader range of donor-to-recipient transfers indicated that Indians essentialized more types of transfers than Americans, but neither sample essentialized monetary transfer. This suggests that results from bodily transplant conditions reflect genuine essentialism rather than broader magical thinking.
\end{abstract}

Keywords: Causal reasoning; Concepts; Culture; Psychology; Psychological essentialism

\section{Introduction}

In Sir Arthur Conan Doyle's (1923) story The Adventure of the Creeping Man, an eminent professor's aide asks Sherlock Holmes to investigate some peculiar changes in the professor's behavior and appearance. The professor has become increasingly aggressive, and his knuckles have become thickened and hairy; he has developed superhuman climbing abilities, and at times he adopts a strange slouching gait. Holmes cleverly deduces that the professor has been injecting himself with a serum derived from langur monkeys

Correspondence should be sent to Meredith Meyer, Department of Psychology, 530 Church Street, University of Michigan, Ann Arbor, MI 48109. E-mail: mermeyer@umich.edu 
in an attempt to maintain his youth and energy. Although the serum does indeed fulfill its intended purpose, it also causes the unfortunate side effects that so worried the professor's aide.

The idea that a serum extracted from a monkey might produce monkey-like appearance and behavior in a human seems clearly at odds with modern-day scientific thinking. However, psychological essentialism would predict that such an idea might nonetheless strike people as intuitively plausible. Psychological essentialism is the theory that people tacitly believe that some internal unseen essence or force determines the common outward appearances and behaviors of the members of a natural kind (Gelman, 2003; Medin \& Ortony, 1989). For instance, a monkey's gait, temperament, and climbing abilities are seen as arising from an internal kind-specific monkey essence. In the case of the "creeping man," the professor's monkey-like behaviors would thus be attributed to the transfer of some of the monkey's essence from inside the monkey - the essence's natural hometo the insides of the professor.

Numerous studies indicate that essentialism underlies much of how people reason about natural kinds. Infants, toddlers, and preschoolers often generalize internal features and behaviors based on category membership, even when category membership and perceptual attributes conflict (e.g., preschoolers expect that a property attributed to a leafinsect will be found in other dissimilar-looking insects rather than a similar-looking leaf). These results suggest a strong belief in the importance of the non-obvious in determining category structure, which in turn licenses inductive inferences (Dewar \& Xu, 2009; Gelman \& Coley, 1990; Gelman \& Markman, 1986, 1987; Graham, Kilbreath, \& Welder, 2004). Additionally, both children and adults expect animals to maintain their kind membership and species-typical behaviors even if external superficial features of the animal or its environment are changed (e.g., Gelman \& Wellman, 1991; Keil, 1989). Notably, the underlying basis is also seen as causal; people privilege internal causal features as bases for categorization over non-causal or outward features (Ahn, Kim, Lassaline, \& Dennis, 2000; Gelman \& Gottfried, 1996; Gelman \& Kremer, 1991; Gottfried \& Gelman, 2005). Finally, people often construe certain categories as sharply bounded, natural, and immutable rather than invented and fluid - a pattern of thinking that is readily explained if people attribute an inalterable and naturally occurring essence to these categories (Bastian \& Haslam, 2006; Haslam, Bastian, Bain, \& Kashima, 2006; Rhodes \& Gelman, 2009; Taylor, Rhodes, \& Gelman, 2009).

One need not have beliefs about the precise nature or location of an essence to believe that it exists and causes common features of category members. Rather, essentializing may in some cases simply involve a belief that there is something deep, internal, and unalterable that is causally responsible for an individual's properties; this is often referred to as an essence "placeholder" (Gelman, 2003; Medin \& Ortony, 1989). Importantly, however, even though people need not have beliefs about the specific location of essence, essences are thought to reside in internal parts (Gelman \& Wellman, 1991; Gottfried \& Gelman, 2005; Newman \& Keil, 2008). If essences are thought to pervade the internal parts of people and animals, and to have causal powers, then the transfer of internal parts from one individual to another may be thought to cause the recipient to take on some of 
the donor's characteristics. This is, of course, precisely the premise behind Conan Doyle's "Creeping Man." The current study focuses on this hypothesized pattern of essentialist thinking, examining whether people systematically believe that transfer of various internal bodily elements could cause recipients to become more like their donors.

We studied this hypothesized pattern of reasoning about bodily element transfers (hereafter referred to simply as "transplants") by surveying two culturally distinct samples, people living in the United States and in India. Psychological essentialism would be reflected by the belief that transplants might confer the traits or characteristics of a donor onto a recipient. Investigating such a reasoning bias in this domain serves to extend prior work on psychological essentialism in several important ways. First, many of the essentialist predictions that have been documented to date actually have some empirical support or grounding in reality: For instance, it is sensible to expect that members of the same animal kind would share similar internal features, and that changes to the outward appearance of an animal would not interfere with its membership in a species or its innately determined behaviors. However, there is no scientific model to account for why transplants might lead to transference of features. Thus, evidence of essentialist reasoning about transplants would provide especially strong evidence for the far-reaching nature of this style of thinking, because it would reflect a reasoning error.

The present studies also test the extent to which essentialist reasoning extends to the social domain. The majority of studies on essentialism to date have focused on beliefs about natural kinds, particularly animals. However, a number of researchers have proposed that people often hold essentialist beliefs about social kinds (Allport, 1954; Astuti, Solomon, \& Carey, 2004; Birnbaum, Deeb, Segall, Ben-Eliyahu, \& Diesendruck, 2010; Diesendruck \& Haber, 2009; Diesendruck \& haLevi, 2006; Gelman \& Heyman, 1999; Gelman, Taylor, \& Nguyen, 2004; Gil-White, 2001; Haslam, Rothschild, \& Ernst, 2000; Hirschfeld, 1996; McIntosh, 2009; Prentice \& Miller, 2007; Rhodes \& Gelman, 2009; Rothbart \& Taylor, 1992), and, importantly, that essentialist beliefs may be linked to stereotyping and social prejudice (Allport, 1954; Bastian \& Haslam, 2006; Keller, 2005; Leslie, in press a; Rothbart \& Taylor, 1992; Smiler \& Gelman, 2008). Thus, understanding the nature and extent of social essentialism is of considerable interest. However, previous work on social essentialism has focused primarily on race, gender, and ethnic categories. Are these the only social categories that are essentialized, or might essentialist thinking extend to other social categories? The current studies address this question by asking respondents to consider transplants from members of a wide range of social categories (e.g., a philanthropist, a murderer, a homeless person, a person with a different sexual orientation, as well as a person with a different gender), as well as transplants from animals (a pig and a chimpanzee).

These studies also advance our understanding of essentialism by contributing to an ongoing debate regarding the very existence of essentialism. Although many studies suggest the operation of essentialism in people's reasoning about a wide range of categories (Gelman, 2003), one alternative account known as the "minimalist" position denies that people's category-based inferences involve a representation of essence at all (Strevens, 2000). The minimalist position instead suggests that people appeal to non-essentialist 
causal laws (so-called K-laws) linking kind membership with observable properties or behaviors. Strevens further claims that belief in these K-laws is enough to explain the data in favor of essentialism. Taking as an example the process by which one infers that tigers will have stripes, Strevens explains, “... you must believe there is something about tigers that causes them to have stripes, but you do not have to believe that this something is essence. For example, you might have no opinion about what does the causing, or you might think that a mechanism that is not an essence does the causing (as in modern biology), or you might think that it is just a brute fact about the world that being a tiger causes an animal to grow stripes" (2000, p. 154).

According to minimalism, the causal laws linking kinds with observable features are believed to be in effect for an individual so long as that individual has membership in the relevant kind category; consequently, membership in a kind licenses predictions of kind-typical behavior. On the strongest version of this claim, it is membership in a kind, not an essence or any other further causal intermediary, that people appeal to as the basis for predicting category-typical properties. We refer to this account as the "unmediated" version of minimalism, in the sense that kind membership and properties are believed to be directly connected by causal laws (e.g., it is just a "brute fact" that they are causally linked [Strevens, 2000, p. 154; see also Figure 3, p. 155]). Another interpretation of the minimalist position, however, allows that individuals may draw on specific mediating causes linking kind membership and outward properties to draw kind-based inferences, but it suggests that there is not sufficient evidence that these beliefs appeal to essences. We refer to this reading as the "mediated" reading, in the sense that specific mediating links may be represented (though they are described as non-essentialist).

On both the unmediated and mediated views described above, minimalism claims that people's inferences about natural kinds do not involve representation of a causal essence. In contrast, psychological essentialism posits that people believe that individual members of a kind have essences that pervade their internal parts and cause their external kind-typical appearance and behavior. A given individual is a member of a kind and displays kind-typical features because it has this sort of essence.

In many respects, psychological essentialism and minimalism make very similar predictions, and to date no experiment has presented a direct test of the competing positions (but see Ahn et al., 2001; Strevens, 2001, for a review of relevant indirect evidence). The current study was designed to directly test predictions from essentialism and the unmediated reading of minimalism (see the General Discussion for issues related to a mediated reading, specifically to what extent it constitutes a distinct theory from placeholder essentialism, once it is appropriately constrained by the empirical evidence). Specifically, it addressed this issue by asking respondents to consider not just whether transplants would confer aspects of the donor on the recipient, but also whether the recipient's category membership would change to that of the donor. If respondents endorsed the possibility that transplants might transfer characteristics of the donor without changing the recipient's category membership, this would provide empirical support against unmediated minimalism because it would indicate that people were not simply basing predictions of kind-typical behavior on category membership, but rather on an intervening causal force 
capable of being transmitted, and exerting its effects independent of category membership. More generally, it would provide evidence, contra Strevens, that people rely on more than just beliefs in K-laws linking category membership and typical properties in their reasoning. (Interestingly, in the Conan Doyle story, the professor is not said to have become a monkey - and so ceased to be a man - rather, he merely takes on some monkey characteristics. Thus, the pattern of reasoning suggested by the Conan Doyle tale is not readily explained by the unmediated minimalist approach.)

More broadly, investigating people's essentialist beliefs about transplants also potentially provides insight into the factors people may consider when donating and accepting transplants. Transfer of internal body parts is now relatively commonplace across the world; hundreds of thousands of soft tissue and bone transplants take place every year (Lederer, 2008), and the types of organs that can be transplanted successfully are everincreasing. Although medical advances in transplant viability have provided more and more people with improvements in quality and length of life, the need for organs far outstrips the supply (Feeley \& Moon, 2009). Investigating people's implicit beliefs and feelings about transplants may help contribute to our understanding of how people arrive at the decision to become donors. Further, the shortage of human donors has prompted scientists to investigate the possibility of "xenotransplantation," in which organs are transplanted from non-human animals (usually pigs) to humans (McLean \& Williamson, 2005). One outstanding question is whether essentialist beliefs will pose a significant obstacle to the acceptance of xenotransplants.

To date, little research has focused on essentialist beliefs about transplants directly. A number of anecdotal reports from transplant recipients hint at such essentialist thinking, however. In Claire Sylvia's autobiographical account A Change of Heart (1997), for example, Sylvia attributes a series of personality changes following a heart and lung transplant to her donor, claiming that her new cravings for beer, as well as increased assertiveness and "masculine" energy, can be explained by having received the organs of an 18-year-old male motorcycle enthusiast and avid beer drinker. Several studies of attitudes about organ transplants also report evidence consistent with such essentialist reasoning. For example, people often report reluctance to receive organs from animals, and sometimes from humans from different social groups, and consistently explain that reluctance by suggesting that transplants might cause both their appearance and personality to become more similar to those of their donors (Basch, 1973; Belk, 1990; Coffman et al., 1998; Hayward \& Madill, 2003; Sanner, 2001a,b). And in a small survey of heart recipients, a full third of respondents endorsed the possibility of having taken on aspects of their human donor's personality or other psychological properties (Inspector, Kutz, \& David, 2004).

The studies described above certainly suggest that people may hold essentialist beliefs concerning organ transplants. However, the conclusions that can be drawn regarding the prevalence of essentialism are limited, because these studies either focused exclusively on small samples of individuals who had already received a transplant, or the study design consisted of minimally structured interview techniques. To address these limitations, we designed the current studies to target two large culturally distinct samples (American and 
Indian), and we employed a series of structured survey questions directly addressing essentialist construals of transplants.

One systematic psychological study on transplants provides highly relevant evidence regarding our research question. Hood, Gjersoe, Donnelly, Byers, and Itajkura (2011) investigated people's views on receiving transplants from a highly immoral donor (a violent murderer) versus a morally positive donor (a volunteer worker). When asked to consider receiving either a heart or a kidney transplant, participants' ratings of happiness dropped substantially from baseline (i.e., the happiness rating when the identity of the hypothetical donor was unknown) if they were told that the hypothetical donor was a murderer. Further, this decrease was significantly larger than the corresponding increase in happiness that occurred if participants were told that the donor was a volunteer worker, which suggests that individuals were more sensitive to the negativity in a morally objectionable donor than they were to the positivity in a morally upright donor.

Hood and colleagues couch their findings in the larger literature concerned with the notion of "moral contagion," which was pioneered by Paul Rozin and his colleagues. Studies of moral contagion have found that people are extremely uncomfortable with the idea of coming into contact with personal items that belonged to individuals deemed morally negative (e.g., Hitler's sweater). In contrast, contact with morally positive individuals (e.g., Mother Teresa) also affects value judgments (Frazier, Gelman, Wilson, \& Hood, 2009; Newman, Diesendruck, \& Bloom, 2011), but typically it does not elicit comparably large gains in positive emotions, paralleling the effect found by Hood et al. (2011; Nemeroff \& Rozin, 1994; Rozin, Markwith, \& McCauley, 1994; Rozin, Millman, \& Nemeroff, 1986). Nemeroff and Rozin (1994) suggest that one of the reasons that individuals are so uncomfortable with physical contact (albeit indirect) with immoral individuals is that they are concerned about a transfer of essence: "The underlying assumption ... either explicitly or implicitly, seems to be that, through contact, some 'essence' or 'soul stuff,' some as yet undefined contagious entity, may be transmitted” (p. 159).

In their study of organ transplants, Hood et al. (2011) similarly suggest that respondents are concerned that they may become morally contaminated by the murderer's essence, and note that such fears are predicted by psychological essentialism. However, although the results from Hood et al. are indeed consistent with the claim that respondents are employing essentialist reasoning, such reasoning is not necessarily responsible for people's discomfort with the idea of receiving a murderer's organ. To be confident that people are employing essentialist reasoning, one would need evidence that people are concerned about the causal effects of the transplants, in particular that the transplant will cause them to become more like the donor. This belief was not directly examined in Hood and colleagues' fascinating study on organ transplants. Furthermore, we know of only two studies in the broader moral contagion literature that address the causal effects predicted by essentialism. One is an unpublished study demonstrating that both older children and adults reported that wearing Mr. Rogers's sweater would result in friendlier behavior, even when the person wearing it was unaware of its prior owner (Johnson \& Jacobs, 2001). The second is a finding that adults are more likely to expect members of a culture to possess traits of animals they typically ingest versus animals they interact with, 
with one possible interpretation being that ingestion is believed to transfer a causal essence (Nemeroff \& Rozin, 1989).

Absent direct evidence of causal thinking, then, one cannot necessarily attribute Hood and colleagues' findings on organs to psychological essentialism. There are a number of alternative non-causal reasoning patterns that could have led to unhappiness with a murderer's organ. For instance, people might feel "creeped out," or feel that they have been contaminated, or experience other negative emotions when thinking about contact with the organs of a morally negative person. None of these negative reactions necessarily involves fearing that they would become like the donor, and so do not require essentialist thinking. People might also consider the social ramifications of receiving an organ from a criminal, expecting that others might view them with suspicion or disgust. Finally, people might simply assume that a murderer would be more likely to have engaged in unhealthy behaviors that would weaken the physical integrity or function of the organ (e.g., drug and alcohol abuse), thereby rendering it less desirable.

We designed the current studies to investigate essentialism and its implications directly. On the basis of the pervasiveness of essentialist thinking when considering the relation between categories and outward properties in other domains (Gelman, 2003), we predicted that people would also employ essentialist thinking here, and so would report that a transplant would have causal consequences - namely causing the recipient to take on characteristics of the donor. Study 1 was a survey of American respondents, whereas Study 2 employed the same survey with a sample of Indian respondents to investigate the ways that essentialism about transplants may be manifested in these different countries. We also assessed other potential reactions to transplants that were not grounded in essentialist biases. Study 3 served as a control study, assessing whether respondents (both American and Indian) endorsed causal effects for the transfer of something that was non-bodily, namely money. If respondents endorsed causal change for bodily transplants but not for money, this would strengthen the argument that people were displaying genuine essentialism in reasoning about transplants. Finally, Study 4 (also with American and Indian respondents) addressed whether essentializing of bodily transplants depended on whether the bodily element was internal and/or biological.

\section{Study 1}

To address the complexities involved in the expression of essentialist and non-essentialist reasoning about internal bodily elements, we manipulated donor type, transplant type, and recipient identity. We first provide an overview of the survey and then address each of these manipulations below. Surveys started with a vignette introducing a hypothetical transplant, described as necessary for the recipient's continued health. Respondents next viewed a list of possible donors and rank-ordered them according to how much they would like each one to be the donor. Respondents then considered each donor in turn and provided a liking rating indicating how much they liked the idea of each one being a donor, and then provided an open-ended explanation for their liking ratings. 
Finally, they answered four Likert-scale questions, two of which assessed causal-essentialist beliefs, and the other two of which assessed non-essentialist beliefs. ${ }^{1}$ Notably, essentialist and non-essentialist inferences were not mutually exclusive, and an individual could simultaneously endorse both (e.g., a respondent could both endorse the idea that a transplant might confer a donor's traits on the recipient [essentialist] and express concerns that others might view the recipient differently after the transplant [nonessentialist]).

An Essentialism composite score was derived from responses to the two essentialist questions. The first essentialist question, Personality/Behavior, assessed people's beliefs that the transplant would cause the recipient's personality or behavior to become more like the donor's. The second essentialist question, Luck, assessed an alternative form of essentialist thinking by asking whether individuals might expect a transplant to cause fortunate or unfortunate events to befall them - the idea being that one's essence might also be seen as causally involved in bringing about one's circumstances (see Olson, Banaji, Dweck, \& Spelke, 2006; for evidence that even young children negatively evaluate individuals who experience bad luck and extend this judgment to others in the same social group, as well as Callan, Ellard, \& Nicol, 2006 for evidence of adults' beliefs in "immanent justice" - the idea that prior misdeeds causally bring about misfortune or punishment). Endorsement of either the personality/behavior change or luck change questions would constitute evidence for essentialism, because it is these endorsements that explicitly reflect beliefs in the causal relationship between essence and outward properties or circumstances. In other words, both cases entail a change in the recipient of the transplant, whereby the recipient takes on characteristics of the donor (personality/behavior or luck).

Similarly, a Non-Essentialist composite score was derived from responses to the two non-essentialist questions. The first non-essentialist question, Reputation, asked respondents about the degree to which they believed that others might view them more negatively or positively post-transplant. The second non-essentialist question, Creeped Out/ Contaminated, assessed the degree to which respondents anticipated disgust or feelings of dirtiness or contamination upon their receiving the transplant. On the basis of past surveys suggesting essentialist views of organ transplants (Basch, 1973; Belk, 1990; Coffman et al., 1998; Hayward \& Madill, 2003; Sanner, 2001a,b) as well as studies of disgust, contagion, and purity (e.g., Nemeroff \& Rozin, 1994), we predicted that respondents would endorse both kinds of reasoning.

Donor types. Respondents were provided with a wide range of potential donors (Table 1), classified into five groups: similar-to-self, different-from-self, positive, negative, and cross-species. We provided similar-to-self types to assess baseline ratings. That is, we assumed that donors who were similar to the respondent (either through close family ties or possession of similar characteristics and environmental background) would be construed as contributing the most similar essence (and thus effect the fewest changes). Thus, scores for various feelings or beliefs about the effects of these transplants would provide a baseline reference point against which we could compare scores for more dissimilar donor types. Different-from-self types were described as differing from the 
Table 1

Donor types and individual donors in each type for Studies 1-3 and Study 4

\begin{tabular}{|c|c|}
\hline Donor Type & Donor $^{\mathrm{a}}$ \\
\hline \multicolumn{2}{|l|}{ Studies $1-3$} \\
\hline \multirow[t]{2}{*}{ Similar-to-self (baseline) } & Same gender, blood-related family member \\
\hline & Same gender, sexual orientation, age, and background as respondent \\
\hline \multirow[t]{2}{*}{ Different-from-self } & Different gender, same age and background as respondent \\
\hline & Different sexual orientation, same gender, age, and background as respondent \\
\hline \multirow[t]{2}{*}{ Positive } & Same gender, high IQ \\
\hline & Same gender, well known for philanthropy and charity work \\
\hline Negative & $\begin{array}{l}\text { Same gender, convicted of violent murder } \\
\text { Same gender, homeless }\end{array}$ \\
\hline Cross-species & $\begin{array}{l}\text { Pig } \\
\text { Chimpanzee }\end{array}$ \\
\hline \multicolumn{2}{|c|}{ Study 4 (described as same gender) } \\
\hline \multirow[t]{6}{*}{ Positive } & A person with a high IQ \\
\hline & Charity worker who gave money to good causes \\
\hline & Kind person liked by many \\
\hline & Talented artist \\
\hline & Talented mathematician \\
\hline & Talented musician \\
\hline \multirow[t]{6}{*}{ Negative } & Homeless person \\
\hline & Person with a low IQ \\
\hline & Schizophrenic \\
\hline & Thief \\
\hline & Compulsive gambler \\
\hline & Violent murderer \\
\hline
\end{tabular}

Note. actual terminology specifying gender of donors depended on respondents' self-reported gender, obtained prior to survey administration. "Same gender" was termed "man" or "male" for male respondents and "woman" or "female" for female respondents; "different gender" was termed "woman" or "female" for male respondents and "man" or "male" for female respondents; for instance, text for a male respondent for the murderer donor was "man convicted of violent murder."

respondent on a major and culturally salient dimension (gender and sexual orientation). Positive and negative donor types were also included, inspired by past studies of magical contagion and feelings about organ transplants (e.g., Hood et al., 2011; Nemeroff \& Rozin, 1994). Positive donor types were described as possessing positive attributes (being highly intelligent) or performing positive acts (philanthropy). Negative donor types were described as being in negative environmental circumstances (homeless) or having performed negative acts (murder). Finally, respondents considered non-human (cross-species) donors, which we included in light of findings that animal species typically are highly essentialized (Atran \& Medin, 2008; Gelman, 2003; Taylor, Rhodes, \& Gelman, 2009) as well as people's reported discomfort with this type of donor as found in earlier studies (Coffman et al., 1998; Sanner, 2001a,b).

The use of cross-species donor types also provided an opportunity to test the different predictions made by essentialism and unmediated minimalism (Strevens, 2000). Recall 
that according to this view, two claims are central: First, essences are not systematically represented in people's kind-based inferences, and second, individuals appeal instead directly to kind membership as a basis for predicting kind-typical behavior (as kind membership is the necessary condition for "K-laws," or causal laws linking kinds with properties, to be in effect). On this view, respondents should judge that cross-species transplants would bring about changes in personality/behavior or luck only if they also judge that the transplant would bring about a change in category membership, because this interpretation of minimalism holds that it is category membership rather than essence that is believed to be the basis for people's predictions of outward behaviors. In contrast, an essentialist construal of organs would allow for transplants to result in outward changes in the recipient despite the recipient's original category membership remaining the same.

To address the competing claims of essentialism and unmediated minimalism, we added a question for the cross-species items, "If you received the transplant/transfusion from a (pig/chimpanzee), would you be a (pig/chimpanzee) after the transplant/transfusion?" (We did not include this question for within-human transplants, because Strevens does not discuss social categories, and it remains unclear how to extend the minimalist view to encompass them. For example, is a murderer's negative behavior to be attributed to his/her membership in the social category murderers? This is a problematic explanation since one only comes to belong to this social kind by engaging in negative behavior in the first place - namely by murdering someone. So it remains unclear how one could make sense of unmediated minimalism for such categories.) We then analyzed responses on the questions assessing essentialist change only for those individuals who did not endorse category change. On the basis of the wealth of studies indicating the presence of essentialism in other domains of reasoning, we expected our findings to support essentialism rather than unmediated minimalism; that is, we expected that people would still endorse transfer of personality, behavior, or luck, even if they denied that the transplant would change their category membership.

Transplant types. To investigate whether participants would respond differentially to different kinds of transplants, we created three versions of the survey, each one asking about a distinct type of internal physical transfer: a blood transfusion, a DNA transplant, and a heart transplant. However, because receiving a heart from a family member would entail the family member's death, the family member as a potential donor for the heart transplant was omitted. On the basis of findings suggesting that adults believe essence to be widely distributed in the body (Newman \& Keil, 2008), we expected that all three types of transfer would lead respondents to expect essence-based effects, that is, score higher on the Essentialist measure for non-similar-to-self donor types relative to baseline similar-to-self types. Another reason to predict essentialist reasoning for all three transplant types can be found in the numerous expressions and metaphors that bear witness to essentialist beliefs about the heart (e.g., the seat of emotion, kindness, or morality) and blood (e.g., hot- or cold-blooded temperaments). However, given recent advances in biology and genomics, educated adults are well aware that DNA plays a part in causing outward properties and behaviors (though of course people's understanding of the specifics may be sketchy or inaccurate; Mayr, 1982), and in light of this, we expected that 
people would be especially likely to expect a DNA transplant to have a causal influence. This pattern of thinking would lead to higher scores on the Essentialist measure for the DNA transplant relative to the heart transplant and blood transfusion scenarios.

Recipient identity. As a final manipulation, we asked respondents to consider transplants given to either themselves or to their (hypothetical) infants. This manipulation was included to control for the possibility that, when considering themselves as the recipient, people might believe that knowing they had received a transplant might cause them to act more like the donor; for example, respondents might imagine that knowing they had received the organ of a murderer might cause them to behave more violently because they thought that they should. This would result in higher scores on the Essentialist measure, but it would not constitute essentialist reasoning. The inclusion of infants (who would be unaware of the transplant and thus not prone to this "placebo" effect) allowed us to assess beliefs about transplants independent of this concern; no differences, however, were expected along this dimension in terms of its interaction with effects for donor or transplant type (the two major manipulations for which we expected main effects).

\section{Summary of Predictions}

- Liking Ratings: Different-from-self, negative, and cross-species donor types will be liked less than similar-to-self (baseline) donor types; liking for positive donor types will be weakly or not differentiated from similar-to-self types. Such findings would in part replicate those found in previous assessments of moral contagion beliefs (Hood et al., 2011; Nemeroff \& Rozin, 1994) and would replicate studies demonstrating distaste for receiving organs from non-human donors (e.g., Coffman et al., 1998; Sanner, 2001a,b).

- Essentialist Measure: Essentialist beliefs about organ transplants will be revealed by higher scores on the Essentialist measure for other donor types relative to similar-to-self donor types. This will hold true regardless of whether the transplant type is blood, DNA, or heart, demonstrating that essence is construed as pervasive throughout the body, as indicated in past studies of psychological essentialism (e.g., Newman \& Keil, 2008); however, especially high scores were predicted for DNA, given its known (though typically unspecified) role in causing outward features.

- Essentialist Measure and Minimalism: Higher scores on the Essentialist measure for cross-species transplant types relative to similar-to-self types will be observed even when respondents deny that receiving a transplant from a non-human animal will lead to the recipient changing category membership. That is, it will be the transferred essence per se that is represented as a causal force, rather than simply category membership being used as a basis for predicting category-typical features. Such findings would run counter to predictions from an unmediated reading of minimalism, which denies that people systematically represent causal essences in explaining how category-typical behaviors arise (Strevens, 2000).

- Non-Essentialist Measure: Non-essentialist styles of reasoning about transplants will be revealed by higher scores on the Non-Essentialist measure for different-fromself, negative, and cross-species donor types relative to similar-to-self donor types; 
in contrast, positive donor types may be weakly or not differentiated from similarto-self for this style of reasoning. These predictions are based on findings from the moral contagion literature (e.g., Hood et al., 2011; Nemeroff \& Rozin, 1994).

\subsection{Method}

\subsubsection{Participants}

Respondents $(n=104)$ were obtained using Amazon's Mechanical Turk, a crowdsourcing platform that allows people to complete online tasks for compensation. We offered the survey only to individuals in the United States and compensated each respondent $\$ 1.85$ for successful completion. Demographic information from these respondents (obtained through self-report) is displayed in Table 2. Four additional respondents provided data that were discarded due to incorrect answers to attention-check questions embedded in the main survey to ensure data were from actively participating respondents. Additionally, data from two surveys associated with the same IP address were discarded, as this indicated that a single person may have taken the survey twice.

\subsubsection{Survey materials and scoring}

Text of the survey questions appears in Table 3. Each survey began with a vignette stating that the recipient or the recipient's infant needed a transplant or transfusion for continued health. A list of donors was provided for respondents to evaluate, all of which were described as healthy, disease-free, and possessing compatible organs according to the respondent's doctor. We created three versions of the survey (blood, DNA, and heart), each describing the relevant transplant or transfusion. Infant-as-recipient versus self-asrecipient was a within-subjects variable, whereas transplant type (blood, DNA, heart) was

Table 2

Demographic characteristics of respondents in Studies 1-4

\begin{tabular}{llllllc}
\hline & $\begin{array}{c}\text { Study 1 } \\
\text { Americans } \\
(n=104)\end{array}$ & $\begin{array}{c}\text { Study 2 } \\
\text { Indians } \\
(n=140)\end{array}$ & $\begin{array}{c}\text { Study 3 } \\
\text { Americans } \\
(n=34)\end{array}$ & $\begin{array}{c}\text { Study 3 } \\
\text { Indians } \\
(n=29)\end{array}$ & $\begin{array}{c}\text { Study 4 } \\
\text { Americans } \\
(n=136)\end{array}$ & $\begin{array}{c}\text { Study 4 } \\
\text { Indians } \\
(n=253)\end{array}$ \\
\hline Sex (\%) & & & & & & \\
$\quad$ Male & 44.2 & 66.3 & 23.5 & 75.9 & 44.9 & 67.6 \\
$\quad \begin{array}{l}\text { Female } \\
\text { Age (years) }\end{array}$ & 55.8 & 33.7 & 76.5 & 24.1 & 55.1 & 32.4 \\
$\quad$ Mean $(S D)$ & $30.8(9.8)$ & $36.9(12.7)$ & $36.2(12.3)$ & $27.8(10.1)$ & $37.7(11.87)$ & $31.4(10.31)$ \\
Religion (\%) & & & & & & \\
$\quad$ Atheist/agnostic & 29.8 & 0.0 & 27.3 & 0.0 & 25.0 & 1.2 \\
$\quad$ Christian & 59.6 & 16.4 & 65.2 & 6.9 & 66.9 & 16.3 \\
Jewish & 4.8 & 0.0 & 6.1 & 0.0 & 2.2 & 0.0 \\
$\quad$ Hindu & 3.8 & 66.4 & 0.0 & 72.4 & 0.0 & 68.4 \\
Muslim & 1.9 & 10.7 & 0.0 & 3.4 & 0.1 & 9.9 \\
Other or unspecified & 0.0 & 6.4 & 1.4 & 17.3 & 5.9 & 4.2 \\
\hline
\end{tabular}


Table 3

Text of survey questions

\begin{tabular}{|c|c|}
\hline Item & Content ${ }^{\mathrm{a}} /$ Scale \\
\hline Preference & $\begin{array}{l}\text { The following is a list of potential donors. Please rank order the options } \\
\text { according to how much you would like to receive your transplant } \\
\text { from each individual. }\end{array}$ \\
\hline Like & $\begin{array}{l}\text { Would you like to receive your transplant/transfusion from this } \\
\text { potential donor? } \\
\text { 1-7: } 1=\text { Definitely No, } 4=\text { Neutral, } 7=\text { Definitely Yes }\end{array}$ \\
\hline Open-ended & Please provide a brief explanation describing your reasoning. (no scale) \\
\hline $\begin{array}{l}\text { Essentialist: } \\
\text { Personality/behavior }\end{array}$ & $\begin{array}{l}\text { To what extent do you think your personality or behavior might change } \\
\text { to become more like that of this donor after the transplant/transfusion? } \\
\text { 1-7: } 1 \text { = Definitely Would Not Change, } 4=\text { Not Sure, } 7=\text { Definitely } \\
\text { Would Change }\end{array}$ \\
\hline Essentialist: Luck & $\begin{array}{l}\text { To what extent do you think your luck might change if you received } \\
\text { your transplant/transfusion from this donor? } \\
\text { 1-7: } 1 \text { = Become Much Less Lucky, } 4=\text { Stay the Same, } 7 \text { = Become } \\
\text { Much More Lucky }\end{array}$ \\
\hline Non-Essentialist: Reputation & $\begin{array}{l}\text { To what extent do you think that other people might view you differently } \\
\text { if you received your transplant/transfusion from this donor? } \\
1=7: 1 \text { = View Much More Negatively, } 4 \text { = View the Same, } 7 \text { = View Much } \\
\text { More Positively }\end{array}$ \\
\hline $\begin{array}{l}\text { Non-Essentialist: } \\
\text { Creeped out/contaminated }\end{array}$ & $\begin{array}{l}\text { To what extent would you feel "creeped out" or "contaminated" if you } \\
\text { received your transplant/transfusion from this donor? } \\
1-7: 1=\text { Not At All, } 4=\text { Somewhat, } 7=\text { Very }\end{array}$ \\
\hline Category change ${ }^{\mathrm{b}}$ & $\begin{array}{l}\text { If you received the transplant/transfusion from a (pig/chimpanzee), } \\
\text { would you be a (pig/chimpanzee) after the transplant/transfusion? } \\
1-7: 1=\text { Definitely No, } 4=\text { Not Sure, } 7=\text { Definitely Yes }\end{array}$ \\
\hline
\end{tabular}

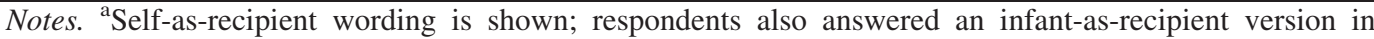
which their hypothetical infants were described as the recipient of the transplant.

${ }^{\mathrm{b}}$ Category change questions were asked only for cross-species (pig and chimpanzee) donors.

a between-subjects variable. An approximately equal number of respondents answered questions about each transplant type, and within each transplant type, approximately half answered questions about their infants as recipients first and the other half about themselves as recipients first (cell sizes ranged from $n=16$ to $n=19$ ). Text of all six scenarios (Blood to Infant, Blood to Self, DNA to Infant, DNA to Self, Heart to Infant, Heart to Self) appears in Appendix A. Following each vignette, respondents rank-ordered their preferences for all 10 donors. This gave respondents the opportunity to consider all donors before responding to the target essentialist and non-essentialist questions.

Feelings and beliefs about each donor were assessed individually. Donors were presented in a randomly determined fixed order. Following each donor, respondents provided a Likert-scale rating of how much they liked the idea of receiving a transplant from each donor (Like), then an open-ended explanation describing the reason behind their rating, and then responses to four Likert-scale questions addressing the target essentialist and non-essentialist reasons: Personality/Behavior (essentialist), Luck (essentialist), Creeped 
Out/Contaminated (non-essentialist), and Reputation (non-essentialist). Essentialist and non-essentialist questions appeared in one of four possible orders determined by a Latinsquare design in approximately equal frequency within each transplant type (blood, DNA, and heart) and recipient type order (infant as recipient first, self as recipient first).

Calculation of the Essentialist composite score was performed in two steps. First, the absolute change in luck from the midpoint value of 4 (= no change in luck) was calculated and then fit to a 1-7 point scale. (This approach allowed comparable values to be generated for both the Personality/Behavior and Luck items, with values of 1 always indicating minimal effects [i.e., either no change in personality/behavior or no change in luck], and 7 indicating maximal effects [i.e., the most change in personality/behavior or change in luck].) Thus, absolute values of $0,1,2$, and 3 were converted to adjusted values of 1, 3, 5, and 7, respectively. Next, the average of the adjusted Luck score and the Personality/Behavior score was calculated, and this average was used as the Essentialist composite score. Calculation of the Non-Essentialist composite score was performed similarly by (a) calculating the absolute change in reputation from the midpoint value of 4 ( $=$ no change in how others viewed the recipient) and then fitting this to a 1-7 point scale and (b) taking the average of the adjusted Reputation score and the Creeped Out/Contaminated score. Cronbach's alpha was very high for both the composite Essentialist measure and the composite Non-Essentialist measure ( $>0.9)$, thus validating the composite measures.

For the cross-species donor types only, a Category Change question came last (after the essentialist and non-essentialist questions), assessing whether cross-species transplants were thought to result in the recipient changing his/her category membership. Finally, two attention check items were also included, embedded within the main survey (To indicate that you are paying attention to this survey, please respond by marking $3 / 6$ for this question). Respondents' data were discarded if they did not answer as requested. Demographic information was obtained after respondents provided their judgments about all donors.

\subsection{Results}

\subsubsection{Overview}

The data are presented in four main sections below: Liking data, Essentialist composite, Test of minimalism, and Non-Essentialist composite. Throughout, ratings for similarto-self donor types were considered a baseline rating, with planned uncorrected pairwise comparisons conducted between similar-to-self (baseline) donor types and all other types (different-from-self, positive, negative, and cross-species). As noted earlier, the heart transplant item was not included for the family member donor trials, as we did not wish to ask about the death of a family member. Thus, the baseline for the heart transplant condition differed from the baseline for the other two conditions, in excluding that one donor. Accordingly, we also conducted supplementary analyses without the family member donor type, to determine whether the results held up when the same baseline was 
used for all three transplant conditions (reported in Table 4, footnote c). Finally, we present data from respondents' open-ended explanations.

In the main analyses of the Likert-scale measures (Liking ratings, Essentialist composite measure, and Non-Essentialist composite measure), ANOVAs were employed using a mixed-factorial 3 (transplant type: blood, DNA, heart) $\times 5$ (donor type: similar-to-self, different-from-self, positive, negative, and cross-species) design, with transplant type as the between-subjects factor and donor type as the within-subjects factor. Preliminary analyses including the within-subjects factor of recipient identity (infant vs. self) and the between-subjects factor of respondent gender demonstrated that neither participated in any interaction that reversed any main effects of donor type or transplant type. Given the complexity of the design, we thus present analyses collapsed across recipient identity and respondent gender.

\subsubsection{Liking data: Rank-ordered preferences and Likert-scale ratings}

Rank-ordered preferences. As ranking data were ordinal and thus not suited for parametric comparisons, a Friedman's test was performed on respondents' rankings for donor

Table 4

Liking, Essentialist, and Non-Essentialist scores by donor type for Study 1 (American respondents) and Study 2 (Indian respondents)

\begin{tabular}{|c|c|c|c|c|c|c|c|c|c|c|c|c|}
\hline \multirow[b]{3}{*}{ Donor Type } & \multicolumn{12}{|c|}{ Measure } \\
\hline & \multicolumn{4}{|c|}{ Liking } & \multicolumn{4}{|c|}{ Essentialist } & \multicolumn{4}{|c|}{ Non-Essentialist } \\
\hline & $M$ & $S D$ & $t^{\mathrm{a}}$ & Sig. ${ }^{\text {b }}$ & $M$ & $S D$ & $t^{\mathrm{a}}$ & Sig. ${ }^{b}$ & $M$ & $S D$ & $t^{\mathrm{a}}$ & Sig. ${ }^{b}$ \\
\hline \multicolumn{13}{|l|}{ American respondents } \\
\hline Similar-to-self (ba & 45 & 0.79 & - & - & 1.54 & 0.81 & - & - & 1.42 & 0.68 & - & - \\
\hline Positive & 02 & 0.91 & 5.96 & $* *$ & 84 & 1.10 & 4.00 & $* *$ & & 0.84 & 4.26 & $* *$ \\
\hline $\mathrm{Di}$ & 87 & 1.34 & 12.57 & * & 67 & 0.85 & 1.96 & 0.06 & 97 & 0.92 & 6.94 & ** \\
\hline ve & 53 & 1.72 & 17 & $*$ & 36 & 0.96 & 3.96 & * & 24 & 1.42 & 14.60 & ** \\
\hline Cros & 48 & 1.62 & 23.82 & $* *$ & 22 & 1.39 & 5.51 & $* *$ & & 1.94 & 17.56 & $* *$ \\
\hline \multicolumn{13}{|l|}{ Indian respondents } \\
\hline Similar-to-self (basel & 10 & 1.10 & - & - & 2.44 & 1.30 & - & - & .42 & 1.52 & - & - \\
\hline & 94 & 1.01 & 1.59 & 0 & 2.94 & 1.42 & 6.09 & $* *$ & 71 & 1.38 & 4.09 & $* *$ \\
\hline Diffe & .54 & 1.40 & 14.33 & $* *$ & 2.65 & 1.23 & 2.66 & $*$ & 83 & 1.36 & 4.67 & $* *$ \\
\hline Negative & 3.75 & 1.41 & 16.53 & $* *$ & 2.78 & 1.24 & 3.72 & $* *$ & 3.47 & 1.35 & 8.82 & $* *$ \\
\hline Cross-species & 1.94 & 1.51 & 27.25 & $* *$ & 3.61 & 1.70 & 8.77 & $* *$ & 5.19 & 1.54 & 17.29 & $* *$ \\
\hline \multicolumn{13}{|c|}{ 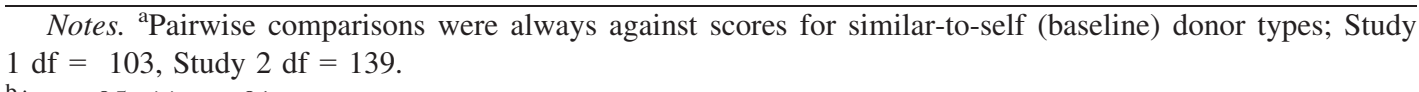 } \\
\hline \multicolumn{13}{|c|}{$\begin{array}{l}\text { 'Similar-to-self baseline for the DNA and Blood conditions included scores for both the close family member } \\
\text { and an individual of same gender, age, sexual orientation, and background. However, as noted in the main } \\
\text { text, the baseline for the Heart condition only included scores for the latter (excluding the close family mem- } \\
\text { ber). We therefore also conducted secondary analyses equating for baseline (i.e., employing only the same } \\
\text { gender, age, sexual orientation, and background donors as baseline), which replicated all ANova donor type } \\
\text { main effects and patterns of significant and nonsignificant results from paired comparisons for both American } \\
\text { and Indian samples. Thus, results from this secondary analysis are entirely consistent with those reported in } \\
\text { the primary analysis. }\end{array}$} \\
\hline
\end{tabular}


types. We collapsed across transplant type (blood, DNA, heart) for simplicity, leaving transplant type to be explored in detail in the main parametric ANOvA analysis of Likertscale Liking ratings. Rankings significantly differed from each other, Friedman's $\chi^{2}(4)=353.42, p<.001$. Wilcoxon signed-ranks tests between similar-to-self and all other donor types revealed that similar-to-self types were preferred significantly more than all other donor types (different-from-self: $Z=8.74$, positive: $Z=6.02$, negative: $Z=8.82$, cross-species: $Z=8.85$, all $p$ s $<.001)$.

Likert-scale ratings. The ANOVA (described above in the Results 2.2.1 overview) revealed a main effect of donor type on liking ratings, $F(4,404)=273.56, p<.001$, $\eta_{\mathrm{p}}^{2}=73$. Paired comparisons of similar-to-self (baseline) types against all other types revealed that transplants from similar-to-self types were liked significantly more than transplants from all other types (Table 4), a pattern consistent with that revealed in the preference rankings. No other main effects or interactions were observed.

\subsubsection{Essentialist composite}

The ANOVA (see Results overview) revealed a main effect of donor type on the Essentialist composite measure, $F(4,404)=17.99, p<.001, \eta_{\mathrm{p}}^{2}=0.15$. Paired comparisons of similar-to-self (baseline) types against all other types revealed that transplants from similar-to-self types had lower scores than all other donor types, $p s \leq .06$ (Table 4). There was also a main effect of transplant type, $F(2,101)=3.18, p=.05, \eta_{\mathrm{p}}^{2}=0.06$, with post-hoc Tukey comparisons showing that DNA received significantly higher scores $(M=2.09, S D=0.93)$ than blood $(M=1.57, S D=0.70), p=.04$, with scores for heart intermediate and not different from the other two $(M=1.82, S D=0.96)$, $p s>.05$. No other main effects or interactions were observed; most important, transplant type did not interact with donor type $(F(8,404)=1.35, p=.21)$, indicating that the main effect seen for donor type that was indicative of essentialism was not restricted to considerations of DNA transplants. American respondents thus broadly endorsed the possibility that transplants from a range of individuals could cause changes in the recipient's outward features or circumstances. This result provides evidence for essentialist reasoning.

It is arguably the case that the Personality/Behavior item (i.e., To what extent do you think your personality or behavior might change to become more like that of this donor after the transplant/transfusion?) is the most direct measure of what is typically considered essentialist thinking. Although our main analysis focused on the composite Essentialist measure including the Luck item, we also conducted a secondary analysis to ensure that patterns remained the same when focusing exclusively on the more canonical Personality/Behavior item. Analyses did indeed replicate results seen for the composite Essentialist measure, namely showing (a) a significant main effect of donor type $(F(4$, $404)=11.56, p<.001, \eta_{\mathrm{p}}^{2}=0.10$ ) with paired comparisons indicating that scores for all other donor types were significantly higher than for similar-to-self types, (b) a significant main effect of transplant type $\left(F(1,101)=5.65, p=.005, \eta_{\mathrm{p}}^{2}=0.10\right)$, with post-hoc Tukey comparisons indicating that scores for DNA were higher than blood $(p=.003)$, with heart intermediate and not different from either, and (c) no interaction between 
donor type and transplant type $(F(4,404)=1.29, p=.25)$. Thus, this secondary analysis is entirely consistent with the primary analysis of the composite item.

Individual response patterns. The distribution of individual response patterns on the Essentialist measure is presented in Table 5, focusing on comparisons between similar-toself and all other donor types. For each non-similar-to-self donor type, we present the proportion of respondents providing the following three response patterns: (a) an average score on the Essentialist measure that was lower for the non-similar-to-self type than the similar-to-self type (a difference inconsistent with essentialism), (b) an average score on the Essentialist measure that was equal for the non-similar-to-self and similar-to-self types (also inconsistent with essentialism), and (c) an average score on the Essentialist measure that was higher for the non-similar-to-self type than the similar-to-self type (consistent with essentialism). If individuals did not expect essentialist effects, the predicted distribution of individual responses would consist mostly of Pattern 2 responses (equal scores), with lower and equal numbers of Pattern 1 and Pattern 3 responses. If, on the other hand, individuals were employing essentialism, responses would be skewed toward Pattern 3 (more Pattern 3 responses than Pattern 1 responses). This was indeed the case; binomial tests comparing the number of individuals reporting higher scores on non-similar-to-self types versus the number of individuals reporting lower scores on non-similarto-self types were significant for all four donor types, $p \mathrm{~s}<.03$. Response patterns indicating essentialism ranged from $31 \%$ of the time (for different-from-self types) to $52 \%$ of the time (for cross-species types).

\subsubsection{Test of minimalism: Category change and essentialist reasoning}

Recall that according to an unmediated reading of the minimalist hypothesis (Strevens, 2000), people explain individuals' behavior based on an appeal to category membership, rather than a causal essence. This view would thus predict that changes in personality, behavior, or luck would be endorsed only in cases when respondents also endorsed change in category membership. Essentialism, however, allows for endorsement of change in personality, behavior, or luck absent endorsement of category change, because

\section{Table 5}

Proportion of respondents providing each of three response patterns on essentialist measure in Study 1 (American respondents) and Study 2 (Indian respondents)

\begin{tabular}{|c|c|c|c|c|}
\hline \multirow[b]{2}{*}{ Response Pattern } & \multicolumn{4}{|c|}{ Donor Type } \\
\hline & Different-from-Self & Positive & Negative & Cross-Species \\
\hline \multicolumn{5}{|l|}{ American respondents } \\
\hline Essentialism score lower than similar-to-self & 0.15 & 0.10 & 0.08 & 0.10 \\
\hline Essentialism score equal to similar-to-self & 0.53 & 0.51 & 0.43 & 0.38 \\
\hline Essentialism score higher than similar-to-self & 0.31 & 0.38 & 0.48 & 0.52 \\
\hline \multicolumn{5}{|l|}{ Indian respondents } \\
\hline Essentialism score lower than similar-to-self & 0.21 & 0.14 & 0.24 & 0.13 \\
\hline Essentialism score equal to similar-to-self & 0.35 & 0.28 & 0.24 & 0.17 \\
\hline Essentialism score higher than similar-to-self & 0.44 & 0.58 & 0.52 & 0.70 \\
\hline
\end{tabular}


the causal agent-essence-can be transferred. To address these competing claims, we reexamined scores on the Essentialist composite measure as they related to scores on the category change questions (i.e., If you received the transplant/transfusion from a (pig/ chimpanzee), would you be a (pig/chimpanzee) after the transplant/transfusion?). Scores on the Essentialist measure for cross-species and similar-to-self donor types were again compared, but this time including only scores from individuals who endorsed absolutely no category change for any cross-species transplants $(n=85)$. Thus, we examined whether people would display essentialist reasoning even when they wholly denied any possibility of the recipient changing category. Scores for similar-to-self were again considered baseline and compared against scores for the cross-species donor types in a 2 (donor type: similar-to-self vs. cross-species) $\times 3$ (transplant type: blood, DNA, heart) ANOVA.

A main effect of donor type was observed, $F(1,82)=18.04, p<.001, \eta_{\mathrm{p}}^{2}=0.18$, with scores for cross-species types higher $(M=1.97, S D=1.29)$ than for similar-to-self types $(M=1.45, S D=0.74)$. There were no other main effects or interactions. Thus, respondents reported that a cross-species transplant could lead to outward changes in the recipient even when denying that that the transplant would change the recipient's category membership. This result is inconsistent with unmediated minimalism and consistent with the idea that respondents expected transplants to transfer causal essence.

\subsubsection{Non-Essentialist composite}

The ANOVA (see Results overview) revealed a main effect of donor type on the NonEssentialist measure, $F(4,404)=198.07, p<.001, \eta_{\mathrm{p}}^{2}=0.66$. Paired comparisons of similar-to-self (baseline) types against all other types revealed that transplants from similar-to-self types had significantly lower scores than all other donor types (Table 4), suggesting that respondents engaged in non-essentialist explanations for reasoning about why transplants from certain types are desirable or not. No other main effects or interactions were significant.

\subsubsection{Open-ended explanations}

We identified seven non-mutually exclusive categories of open-ended explanations: (a) Safety/Health (explanations that appealed to the safety of the procedure or health of the donor or recipient), (b) Morality (explanations that mentioned the moral status of the donor or the overall moral ramifications of the transplant procedure), (c) Creeped Out/ Reputation (explanations that described feeling disgusted or creeped out, or beliefs that others might view the recipient differently; these are the same dimensions that contributed to the Non-essentialist composite measure addressed by close-ended questions), (d) Appeal to Category (explanations that offered the donor's category membership as the reason for a decision, apparently as if to convey that further explanation was unnecessary, (e) Essentialist (explanations that described the possibility of a transplant conferring traits or characteristics to the recipient; these correspond to the Essentialist composite measure addressed by close-ended questions), (f) Denial of Essentialism (explanations that contained explicit rejection of essentialist predictions), and (g) Unclear or Other 
(explanations that did not fall into any of the previous six categories). Prior to formal coding, any mention of specific donor types or transplant types was replaced with neutral "donor X" and "transplant X" text (e.g., "I worry that a heart from a man would be too big" was modified to "I worry that a transplant X from a donor X would be too big"). This was done so that coders would not be biased to identify certain explanation styles preferentially according to donor or transplant type. A primary coder then classified responses into the seven explanation types. A second coder provided classifications for $20 \%$ of responses, and disagreements were resolved through discussion. Agreement for the categories ranged from very good to excellent, with Cohen's kappa ranging from 0.72 to 0.86 (average Cohen's $\kappa=0.79$ ). Sample explanations and classifications are displayed in Table 6, and proportion of respondents providing each type of explanation for the different donor types is displayed in Table 7. Explanations that appealed to safety and health (as well as unclear or other explanations) tended to predominate. However, explanations corresponding with the close-ended Non-Essentialist composite measures were also observed, and appeals to overall moral aspects and category membership were also fairly common. Finally, although respondents sometimes explicitly rejected essentialist effects in their explanations, essentialist explanations were also observed; in fact, a full $34.61 \%$ of respondents gave at least one essentialist explanation across all their responses.

\subsection{Discussion}

This study replicated past findings regarding distaste for transplants from negative, different, and cross-species donor types. We also demonstrated that respondents preferred transplants from similar-to-self types significantly more even than positive donor types. This effect was unexpected given that positive individuals are unlikely by themselves to elicit disgust or moral concerns (e.g., Nemeroff \& Rozin, 1994) and suggests that, when thinking about bodily transplants, the respondents in this study most preferred donors who are most similar to themselves. Although we did not predict this finding, it is readily explained by essentialism: If people think that receiving a transplant may lead to changes in their essence, then they might reasonably dislike the idea of receiving a transplant

Table 6

Sample open-ended explanations according to type

\begin{tabular}{ll}
\hline \multicolumn{1}{c}{ Explanation Type } & \multicolumn{1}{c}{ Sample Explanation } \\
\hline Safety/health & "Worried about disease" \\
Morality & "Because philanthropists are kind-hearted people" \\
Creeped out/reputation & "I will feel very contaminated and creepy" \\
Category label & "Definitely no, because it's a chimpanzee" \\
Essentialist & "The cruel murderer's qualities will come to me" \\
Denial of essentialism & "The heart does not pass along any of those qualities" \\
Unclear/other & "Sounds fine" \\
\hline
\end{tabular}


Table 7

Proportion of respondents providing target open-ended explanation types for Study 1 (American respondents) and Study 2 (Indian respondents) ${ }^{\mathrm{a}}$

\begin{tabular}{|c|c|c|c|c|c|c|c|}
\hline \multirow[b]{2}{*}{ Donor Type } & \multicolumn{7}{|c|}{ Explanation Type } \\
\hline & $\begin{array}{l}\text { Safety/ } \\
\text { Health }\end{array}$ & Morality & $\begin{array}{c}\text { Creeped } \\
\text { Out/Reputation }\end{array}$ & $\begin{array}{l}\text { Category } \\
\text { Label }\end{array}$ & Essentialist & $\begin{array}{c}\text { Denial of } \\
\text { Essentialism }\end{array}$ & $\begin{array}{l}\text { Unclear/ } \\
\text { Other }\end{array}$ \\
\hline \multicolumn{8}{|l|}{ American respondents } \\
\hline Similar-to-self & 0.50 & 0.05 & 0.02 & 0.23 & 0.02 & 0.04 & 0.94 \\
\hline Different-from-self & 0.63 & 0.09 & 0.10 & 0.00 & 0.13 & 0.10 & 0.80 \\
\hline Positive & 0.60 & 0.29 & 0.04 & 0.05 & 0.23 & 0.17 & 0.73 \\
\hline Negative & 0.66 & 0.17 & 0.29 & 0.04 & 0.15 & 0.14 & 0.81 \\
\hline Cross-species & 0.56 & 0.05 & 0.26 & 0.14 & 0.04 & 0.00 & 0.79 \\
\hline \multicolumn{8}{|l|}{ Indian respondents } \\
\hline Similar-to-self & 0.22 & 0.07 & 0.04 & 0.29 & 0.06 & 0.04 & 0.99 \\
\hline Different-from-self & 0.31 & 0.14 & 0.03 & 0.05 & 0.24 & 0.08 & 0.96 \\
\hline Positive & 0.25 & 0.49 & 0.04 & 0.10 & 0.45 & 0.16 & 0.83 \\
\hline Negative & 0.38 & 0.48 & 0.16 & 0.09 & 0.28 & 0.05 & 0.89 \\
\hline Cross-species & 0.30 & 0.04 & 0.11 & 0.16 & 0.09 & 0.01 & 0.90 \\
\hline
\end{tabular}

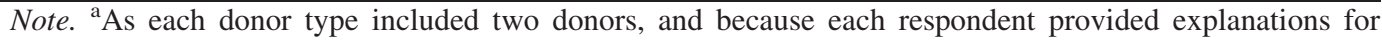
both self-as-recipient and infant-as-recipient, the proportion of respondents providing the different styles of explanations do not add to 1.0 across rows.

from anyone who differs from them, even along a positive dimension. That is, people dislike the prospect of any change in their essence - positive or negative - and so any salient difference between the donor and recipient leads to increased resistance to the transplant. In this way, people's specifically essentialist reasoning about transplants differs from their more general way of reasoning about moral contagions.

Regarding the underlying reasons for people's feelings about various donor types, we found evidence for the role of essentialism. As predicted, essentialism was seen most when reasoning about DNA transplants. However, it was also employed for other transplant types as well, namely for blood transfusions and heart transplants. Further, it was observed when respondents considered transplants both to their infants as well as themselves, suggesting that responses were not driven by expectations of a "transplant placebo" effect, whereby people would predict that knowing about the transplant would be the cause of any changes in the recipient.

It is important to note that obtaining evidence for essentialism required that respondents actively reject formal knowledge about the function of bodily elements. Thus, it is very likely that the survey was a highly conservative measure of the pervasiveness and strength of the essentialist phenomenon. Indeed, average scores on the Essentialist measure were typically low (i.e., always under "3"). However, the effect size obtained for donor type $\left(\eta_{\mathrm{p}}^{2}=0.15\right)$ was large (Kinnear \& Gray, 2004) and suggests that people were highly consistent in reporting essentialist effects for non-similar-to-self donors. Furthermore, respondents engaged in essentialist reasoning about all the different categories under consideration, including social categories as well as non-human species. Individual 
response patterns on the Essentialist composite measure further indicated the strength and pervasiveness of the effect; respondents were significantly more likely to provide scores for non-similar-to-self types that were higher than similar-to-self types (vs. lower), adding more support to the claim that essentialist reasoning was often used when considering transplants from other individuals. As well, respondents' open-ended explanations also frequently invoked essentialist explanations (particularly for human donors differing from self). Finally, we also found that respondents engaged in non-essentialist styles of reasoning when considering the various donor types, reporting concerns about contamination and/or reputation change post-transplant. As with essentialist reasoning, non-essentialist reasoning was seen for considerations of transplants to both the respondents themselves and their infants, across a range of transplant types, and for donors that were both human and non-human.

\section{Study 2}

Study 1 demonstrated essentialist thinking about transfer of internal bodily elements in a sample of Americans. Although these data are indicative of systematically held lay beliefs that transplants can have causal effects, left unanswered is whether these findings would be observed in both countries, or if these patterns of reasoning are particular to a Western sample. In Study 2, we expanded the focus of our study by targeting respondents in India so as to investigate possible cultural similarities and differences in essentialist (and non-essentialist) beliefs about transplants. India is an especially interesting country to examine because it differs from the United States on a number of dimensions that may affect how transplants are conceptualized. For instance, Hindu Indians typically are more concerned with contamination than Westerners - a difference that has been attributed to a high degree of concern with maintaining purity, and a belief that it can be threatened by indirect as well as direct interpersonal contact (e.g., Hejmadi, Rozin, \& Siegal, 2004). Such concerns are prominently featured in dietary laws and customs that regulate what foods may be eaten (Olivelle, 1995), as well as rules regarding the caste systemreflected, for instance, by traditional restrictions of contact or association with the "untouchable" caste (Narula, 1999). In light of such pervasive contamination concerns, it is plausible that when thinking about bodily transplants, contamination-based reasoning (indicated by the Non-Essentialist measure) might predominate or even be employed to the exclusion of causal-essentialist reasoning.

Further, there are sociocultural differences in the regulation of organ transplants that might also contribute to Indians showing stronger contamination concerns. Until 1995, paying donors for organs was legal in India, and commercial transplants were characterized by poor oversight and improper screening of donors, in numerous cases resulting in the transmission of serious viruses such as HIV and hepatitis (Salahudeen et al., 1990). Although the practice was ultimately banned, paying for organs is still a relatively common practice in some areas of the country, with donations often coming from marginalized or impoverished individuals, reportedly often under duress (Jha, 2004; Kalbag, 
2008). In contrast, commercial transplants in the United States have been illegal on the national level since 1984, and laws regulating organ transplants have been more strictly enforced, with infractions occurring very rarely (Panjabi, 2011). In light of this, we predicted that Indians would report higher levels of discomfort with organ transplants, particularly from the "negative" donor type, either because these types are seen as victimized (leading to feelings of guilt), or because they are seen as more unclean (leading to feelings of contamination). It is therefore likely that such feelings would contribute to higher scores on both of the measures of non-essentialist reasoning, namely the "creeped out/contaminated" and "reputation" items.

Thus, given Indians' predicted heightened focus on contamination, as well as specific sociocultural factors surrounding how organ transplants have been regulated and conducted, one might expect an exclusive focus on non-essentialist explanations in an Indian sample. On the other hand, it is also plausible that evidence for essentialism would still be found among the Indian respondents, largely replicating the findings from the American sample. As discussed earlier, non-essentialist explanations can be entertained independent of essentialist explanations, meaning that it is entirely possible that respondents would engage in both styles of reasoning simultaneously. As well, ample literature suggests that essentialist thinking is found across varied cultures (Atran, 1990, 1998; Atran \& Medin, 2008; Gil-White, 2001; Hirschfeld, 1996, 2001; Waxman, Medin, \& Ross, 2007), including Indian cultures (Mahalingam, 2003; Mahalingam, Haritatos, \& Jackson, 2007). Given that essentialism in other domains has been found to be so widespread, we predicted that essentialist thinking about organ transplants would also be found cross-culturally, and thus would be detectable among Indians as well as Americans.

To assess this prediction, we employed the same survey and analyses that were used with Americans. Again, we were interested in examining the degree to which essentialist and non-essentialist styles of reasoning were employed when considering different potential donors.

\subsection{Method}

\subsubsection{Participants}

Respondents $(n=140)$ were obtained using Amazon's Mechanical Turk. We offered the survey only to individuals in India and compensated each respondent $\$ 1.85$ for successful completion. Demographic information from these respondents is displayed in Table 2. Sixty-eight additional respondents provided data that were discarded due to incorrect answers to the attention-check questions. The proportion of respondents failing attention-check questions was much higher in this sample than in the American sample. This is likely due to the higher proportion of individuals in India using Mechanical Turk as a primary source of income rather than a secondary or tertiary source, as is common in the United States (Ross, Irani, Silberman, Zaldivar, \& Tomlinson, 2010); this difference likely increases volume but decreases quality across respondents. Whatever the cause for the discrepancy, answering both attention-check questions correctly by chance would be predicted only $2 \%$ of the time, and thus answers from retained individuals are 
highly likely to be from engaged individuals with proficient English. Additionally, we discarded data from five pairs of surveys that had duplicate IP addresses within each pair, as this indicates a likelihood that these surveys were taken by the same individual twice.

\subsubsection{Survey materials and scoring}

The survey and scoring were identical to that given to American respondents in Study 1. Respondents answered questions about each type of transplant or transfusion; the number of respondents answering questions about heart transplants was higher $(n=56)$ than the other two transplant types (blood $n=44$, DNA $n=40$ ). Within each transplant type, approximately half responded to questions about an infant as recipient first, and the other half responded to questions about the self as recipient first (cell sizes ranged from $n=18$ to $n=24$ in the non-heart conditions; in the heart condition, $n=25$ [infant first] and $n=31$ [self first]).

\subsection{Results}

Analyses exploring the predicted main effects of donor type and transplant type on rank-ordered preferences, Likert-scale liking ratings, Essentialist scores, and Non-Essentialist scores were identical to those used for the American respondents in Study 1, namely non-parametric analyses of rank-ordered preferences and ANOVAs for the remaining measures featuring a 3 (transplant type: blood, DNA, heart) $\times 5$ (donor type: similarto-self, different, positive, negative, cross-species) design. As with American respondents, the infant versus self as recipient variable and respondent gender did not participate in any interactions that reversed any significant main effects of donor or transplant type. Thus, we collapsed across these variables for the final analyses.

\subsubsection{Liking data: Rank-ordered preferences and Likert-scale ratings}

Rank-ordered preferences. Rankings significantly differed from each other, Friedman's $\chi^{2}(4)=398.94, p<.001$. Wilcoxon signed-ranks tests between similar-to-self and all other donor types revealed that rankings for similar-to-self and positive types did not differ $(Z=0.68, p>.05)$, but similar-to-self types were significantly preferred over all other donor types (different-from-self: $Z=9.72$, negative: $Z=9.17$, cross-species: $Z=10.12$, all $p \mathrm{~s}<.001)$.

Likert-scale ratings. The ANOVA (see Study 1 Results overview) revealed a main effect of donor type on liking ratings, $F(4,548)=372.16, p<.001, \eta_{\mathrm{p}}^{2}=0.73$. Scores for similar-to-self types and positive types were not significantly different; however, transplants from similar-to-self types were liked significantly more than from the other three types (different-from-self, negative, and cross-species), a pattern consistent with that seen in the preference rankings (Table 4). There was also a main effect of transplant type, $F(2,137)=4.08, p=.02, \eta_{\mathrm{p}}^{2}=0.06$. Tukey post-hoc tests indicated that DNA donations were liked less $(M=4.14, S D=1.67)$ than heart transplants $(M=4.63, S D=1.30)$, $p=.02$, whereas blood transfusions $(M=4.52, S D=1.54)$ were intermediate and not 
different from the other two, $p \mathrm{~s}>.05$. Finally, these main effects were qualified by a donor type $\times$ transplant type interaction, $F(8,548)=5.07, p<.001, \eta_{\mathrm{p}}^{2}=0.07$. As our main prediction centered on the main effect of donor type, to examine the nature of this interaction we again compared all other donor types against similar-to-self types within each transplant type. Importantly, comparisons of similar-to-self against all other types within each transplant type revealed the same overall pattern described for the main effect of donor type, with the single exception that transplants from similar-to-self types were significantly more liked than transplants from positive types in the blood condition $(t(43)=3.62, p=.001$; whereas they were not differentiated in the overall main effect).

\subsubsection{Essentialist composite measure}

The ANOVA (see Study 1 Results overview) revealed a main effect of donor type on the Essentialist composite measure, $F(4,548)=44.49, p<.001, \eta_{\mathrm{p}}^{2}=0.25$. Paired comparisons of similar-to-self (baseline) types against all other types revealed that transplants from similar-to-self types had significantly lower scores than all other donor types (Table 4), indicating that Indian respondents endorsed essentialist reasoning. There was also a main effect of transplant type, $F(2,137)=4.25, p=.02, \eta_{\mathrm{p}}^{2}=0.06$, with Tukey post-hoc comparisons indicating that DNA transplants $(M=3.29, S D=2.21)$ received higher scores than blood transfusions $(M=2.52, S D=2.11), p=.03$, and heart transplants $(M=2.72, S D=1.87), p=.04$. There were no other main effects or interactions; most important, there was no interaction between donor type and transplant type, indicating that the main effect of donor type indicative of essentialism was not restricted to DNA. Thus, there was clear evidence for essentialist reasoning in Indian respondents, which was especially strongly (but not exclusively) observed for beliefs about DNA transplants.

As in Study 1, we also examined scores on the Personality/Behavior item considered separately (a more canonical measure of essentialism) to determine if patterns were similar on this item to patterns on the composite Essentialist measure. The results were largely replicated, with findings indicating (a) a main effect of donor type $\left(F(4,548)=16.40, p<.001, \eta_{\mathrm{p}}^{2}=0.16\right)$ with paired comparisons indicating that scores for similar-to-self types were lower than for all other donor types and (b) a main effect of transplant type $\left(F(1,137)=9.70, p<.001, \eta_{\mathrm{p}}^{2}=0.12\right)$ with post-hoc Tukey comparisons indicating that scores for DNA were higher than for both heart and blood $(p s<.01)$, whereas heart and blood did not differ from each other. However, unlike results for the Essentialist composite score, there was a significant donor type $\times$ transplant type interaction, $F(4,548)=2.63, p=.03, \eta_{\mathrm{p}}^{2}=0.04$. Paired-samples $t$-tests revealed that scores on similar-to-self were not significantly different from either different-from-self $(p=.12)$ or negative $(p=.10)$ donor types within heart transplants. All other comparisons, however, were significant, with similar-to-self receiving lower scores. Thus, aside from a slight attenuation of the main effect of donor type within heart transplants, results were consistent with the primary analysis of the composite essentialism item; most important, patterns consistent with essentialist thinking were shown for a variety of donor types and across a range of transplant types. 
Individual response patterns. The distribution of responses on the Essentialist measure are presented in Table 5, again (as with Americans) focusing on comparisons between similar-to-self and all other donor types. Responses consistent with essentialism were seen for all non-similar-to-self donor types, with individuals' scores consistent with essentialism (i.e., higher relative to similar-to-self) ranging from almost $44 \%$ (for different-fromself types) to $70 \%$ (for cross-species types). Binomial tests comparing the number of individuals reporting higher scores on non-similar-to-self types versus the number of individuals reporting lower scores on non-similar-to-self types were significant for all four donor types, $p$ s $<.001$.

\subsubsection{Test of minimalism: Category change and essentialist reasoning}

People's responses to the essentialist questions relative to responses on the category change questions were again compared to assess the claims of the unmediated minimalist approach. Scores on the Essentialist measure were compared for cross-species and similar-to-self donor types using data only from respondents who had uniformly rejected the idea of a transplant causing a change in category membership $(n=74$; the same analysis used for Americans). There was a main effect of donor type, $F(1,71)=24.47, p<.001$, $\eta_{\mathrm{p}}^{2}=0.26$, with scores for cross-species types higher $(M=3.07, S D=1.81)$ than for similar-to-self types $(M=2.10, S D=1.29)$. There were no other main effects or interactions. Indian respondents therefore showed essentialist reasoning regarding cross-species transplants even when they did not expect the transplant to exert any change whatsoever in the recipient's category membership.

\subsubsection{Non-Essentialist composite measure}

The ANOva (see Study 1 Results overview) revealed a main effect of donor type on the Non-Essentialist measure, $F(4,548)=201.94, p<.001, \eta_{\mathrm{p}}^{2}=0.60$. Paired comparisons of similar-to-self (baseline) types against all other types showed that similar types received significantly lower scores than all other types (Table 4). There was also a main effect of transplant type, $F(2,137)=4.21, p=.02, \eta_{\mathrm{p}}^{2}=0.06$. Tukey post-hoc comparisons indicated that DNA transplants $(M=3.76, S D=2.16)$ received higher scores than both blood transfusions $(M=3.12, S D=2.04), p=.04$, and heart transplants $(M=3.14, \quad S D=1.80), \quad p=.02$. Finally, there was a significant donor type $\times$ transplant type interaction, $F(8,548)=3.80, p<.001, \eta_{\mathrm{p}}^{2}=0.05$. Because our main prediction centered on the main effect of donor type, to examine the nature of this interaction, we again compared all other donor types against similar-to-self types within each transplant type. The pattern of results was largely the same as the overall main effect, with the exception that for heart transplants, scores for similar-to-self types were no longer different from positive types $(t(55)=1.65, p=.11)$ or differentfrom-self types $(t(55)=1.61, p=.11)$. Thus, on the whole, there was still strong evidence for non-essentialist reasoning in Indian respondents for a wide range of donor types, with only slight attenuation of this effect observed within heart transplant scenarios. 


\subsubsection{Open-ended explanations}

Coding of open-ended explanations was identical to the procedure used for American responses. Agreement between two coders on 20\% of the responses ranged from good to excellent, with Cohen's kappa ranging from 0.67 to 0.81 (average $\kappa=0.74$ ). As with Americans, concerns with safety and health (as well as unclear or other types of explanations) predominated, but essentialist explanations were observed as well, and in fact were more commonly seen in Indians' responses $52.14 \%$ of Indians gave at least one essentialist explanation across all their responses, compared to about a third of Americans). Appeals to the morality of the donor were also notably prominent (Table 7).

\subsection{Discussion}

Patterns of preferences and liking were remarkably similar to those seen in Americans. In particular, similar-to-self donor types were typically preferred over other types of donors (different-from-self, negative, and cross-species types), though for Indian respondents, this difference was not significant when considering positive types. Evidence for essentialist thinking similar to that of Americans was also revealed in the Indian sample. Respondents endorsed the possibility of outward characteristics (personality/behavior or luck) changing upon receiving the transplant to become more like those of the donor. This pattern of reasoning was seen both for human donor types who differed from the recipient as well as cross-species donor types, indicating that, as with Americans, essentialist construals of transplants extended beyond other species to other types of people. Finally, Indians also indicated non-essentialist concerns with transplants, reporting they would feel contaminated and/or fear social disapproval if they were to receive transplants from non-similar-to-self types. Taken together, the data indicate that the Indian sample entertained both causal and non-causal styles of explanations when reasoning about transplants from other individuals.

\section{Study 3}

In both Study 1 (with Americans) and Study 2 (with Indians), respondents provided higher scores on the Essentialist measure for all other donor types relative to donors similar to themselves. We interpret this pattern as constituting evidence for essentialist reasoning about transplants, because it suggests that people expect transplants to transfer aspects of a donor to a recipient. Alternatively, however, the data may reflect a broader magical thinking style, in which individuals expect that any kind of transfer from one person to another has the capacity to transfer aspects of the original owner to the new owner. Although this would be a noteworthy finding in its own right, this would not suggest that respondents represented essence as exclusively internal, bodily, and transferable, 
but rather that transplants are one of many ways in which the transfer of anything at all can confer traits of a donor on a recipient.

To address this alternative explanation, we created a control study in which respondents (both American and Indian) were asked to consider receiving money rather than a transplant from the various donor types. Money was described as being transferred from the donor's account to the recipient's account, again without any direct personal interaction. In light of our original hypothesis - namely that Studies 1 and 2 reflected people's tendency to represent essence as a causal force within the body-we predicted the absence of essentialist thinking in the money transfer scenario.

\subsection{Method}

\subsubsection{Participants}

Respondents were obtained using Amazon's Mechanical Turk (American $n=34$; Indian $n=29$ ). The number of respondents was approximately equal to that of each of the bodily transplants in the prior studies. We offered the survey only to individuals in the United States (for the American sample) and India (for the Indian sample) and compensated each respondent $\$ 1.85$ for successful completion. Data from two additional American respondents and 17 additional Indian respondents were discarded due to incorrect answers to the attention-check questions. Additionally, we discarded data from the Indian sample from nine surveys that had duplicate IP addresses, as this indicates a likelihood that these surveys were taken by the same individual more than once.

\subsubsection{Survey materials and scoring}

Surveys opened with a vignette describing a money donation. The donation was described as helping to pay for an expensive and necessary medical treatment, an aspect that allowed the necessity and urgency of the donation to be roughly equivalent to that of the transplant scenarios. The amount of money was specified as $\$ 2,000$ for the American sample and 100,000 rupees for the Indian sample; amounts were approximately equal based on the dollar-to-rupee exchange rate the month the study was run. The remaining content of the survey was otherwise identical to that of Studies 1 and 2 except that animal donor types were excluded, as animals obviously do not possess money and thus could not serve as potential donors. (In addition because animals were excluded, no category change questions were asked, as these had originally been provided only for the animal donor types.) The eight human donors were again classified into the same similar-to-self, different-from-self, positive, and negative donor types. Approximately, half of the respondents within each country sample (American and Indian) responded to questions about an infant as recipient first, and the other half responded to questions about the self as recipient first (cell sizes ranged from $n=14$ to $n=17$ ). Scoring and calculation of the Essentialist and Non-Essentialist measures were identical to Studies 1 and 2. Exact wording of money transfer vignettes appears in Appendix A. 


\subsection{Results}

\subsubsection{Overview}

Infant- versus self-as-recipient and gender of respondent did not participate in any interactions that reversed any donor type main effects found in preliminary analyses. They were thus removed from the primary reported analyses. As in Studies 1 and 2, preference rankings were analyzed by a non-parametric Friedman's test, and American and Indian samples were analyzed separately. Likert-scale measures (Liking ratings, Essentialist scores, and Non-Essentialist scores) were analyzed in separate one-way within-subjects ANOVAS examining the factor of donor type (similar-to-self, different-from-self, positive, and negative). A final analysis compared essentialist beliefs across Studies 1, 2, and 3, thereby making comparisons based on country (United States vs. India) as well as transplant type (bodily vs. non-bodily money control).

\subsubsection{Liking data: Rank-ordered preferences and Likert-scale ratings}

Rank-ordered preferences. For Americans, rankings significantly differed from each other, Friedman's $\chi^{2}(3)=80.41, p<.001$. Wilcoxon signed-ranks tests between similarto-self and all other donor types revealed that rankings for similar-to-self and positive types did not differ $(Z=0.41, p>.05)$, but similar-to-self types were significantly preferred over the other two donor types (different-from-self: $Z=4.46$, negative: $Z=5.10$, both $p s<.001)$. For Indians, rankings also significantly differed from each other, Friedman's $\chi^{2}(3)=67.33, p<.001$. Wilcoxon signed-ranks tests between similar-to-self and all other donor types indicated that rankings for similar-to-self and positive types again did not differ $(Z=0.93, p>.05)$, but similar-to-self types were significantly preferred over the other two donor types (different: $Z=4.63$, negative: $Z=4.51$, both $p \mathrm{~s}<.001$ ). Americans and Indians thus showed the same pattern, significantly preferring similar-toself donor types over different and negative types, but not differentiating between similar-to-self and positive donor types.

Likert-scale ratings. For Americans, the ANOVA revealed a main effect of donor type on liking ratings, $F(3,99)=90.86, p<.001, \eta_{\mathrm{p}}^{2}=0.73$. Scores for positive and similar-toself types were not differentiated; however, donations from similar-to-self types were liked significantly more than those from the other two types (different-from-self and negative; Table 8). An identical pattern was seen in the Indian sample; there was a main effect of donor type on liking ratings, $F(3,84)=109.50, p<.001, \eta_{\mathrm{p}}^{2}=0.80$, with scores for positive and similar-to-self types not differentiated, and donations from similar-to-self types liked significantly more than those from the other two types (different-from-self and negative; Table 8), a pattern consistent with that observed in the preference rankings.

\subsubsection{Essentialist composite measure}

For Americans, there was no significant main effect of donor type on the Essentialist measure, $F(3,99)=1.71, p=.17$. We nevertheless conducted paired comparisons of similar-to-self (baseline) types against all other types, which revealed that scores for 
Table 8

Liking, Essentialist, and Non-Essentialist scores by donor type for Study 3 (money transfer control)

\begin{tabular}{|c|c|c|c|c|c|c|c|c|c|c|c|c|}
\hline \multirow[b]{3}{*}{ Donor Type } & \multicolumn{12}{|c|}{ Measure } \\
\hline & \multicolumn{4}{|c|}{ Liking } & \multicolumn{4}{|c|}{ Essentialist } & \multicolumn{4}{|c|}{ Non-Essentialist } \\
\hline & $M$ & $S D$ & $t^{\mathrm{a}}$ & Sig. $^{b}$ & $M$ & $S D$ & $t^{\mathrm{a}}$ & Sig. ${ }^{\mathrm{b}}$ & $M$ & $S D$ & $t^{\mathrm{a}}$ & Sig. ${ }^{\mathrm{b}}$ \\
\hline \multicolumn{13}{|l|}{ American respondents } \\
\hline Similar-to-self (baseline) & 6.21 & 1.12 & - & & 1.80 & 1.39 & - & - & 1.09 & 0.88 & & \\
\hline Different-from-self & 5.73 & 1.18 & 2.96 & $*$ & 1.54 & 1.10 & 2.13 & $*$ & 1.15 & 0.86 & 0.68 & ns \\
\hline Positive & 6.28 & 0.80 & 0.57 & ns & 1.87 & 1.34 & 0.52 & ns & 1.18 & 0.77 & 0.80 & ns \\
\hline Negative & 2.96 & 1.54 & 10.19 & $* *$ & 1.77 & 1.40 & 0.15 & ns & 2.65 & 1.51 & 7.27 & $* *$ \\
\hline \multicolumn{13}{|l|}{ Indian respondents } \\
\hline Similar-to-self (baseline) & 6.04 & 0.92 & - & & 2.51 & 1.75 & - & - & 2.24 & 1.36 & & \\
\hline Different-from-self & 5.07 & 1.02 & 4.55 & $* *$ & 2.27 & 1.42 & 1.16 & ns & 2.34 & 1.31 & 0.55 & ns \\
\hline Positive & 6.04 & 0.72 & 0.00 & ns & 2.53 & 1.57 & 0.16 & ns & 2.16 & 1.32 & 0.79 & ns \\
\hline Negative & 2.27 & 1.24 & 13.47 & $* *$ & 2.59 & 1.51 & 0.31 & ns & 3.46 & 1.26 & 4.22 & $* *$ \\
\hline
\end{tabular}

Notes: ${ }^{\text {a}}$ Pairwise comparisons were always against scores for similar-to-self (baseline) donor types; American $\mathrm{df}=33$, Indian $\mathrm{df}=28$.

$\mathrm{b}^{*} p<.05 ; * * p<.01$.

similar-to-self types were not significantly different from either positive or negative types, and in fact were significantly higher than different-from-self types (the opposite direction of that obtained in Study 1; Table 8). A similar nonsignificant effect was seen for donor type in Indians as well, $F(3,84)=1.13, p=.34$. We similarly conducted paired comparisons of similar-to-self types against the other three types, which showed that scores for similar-to-self types did not differ from any other type (Table 8). Thus, the prediction that money donations would not result in causal-essentialist thinking was supported.

Examination of Personality/Behavior scores alone (the more canonical measure of essentialism) similarly did not reveal evidence of essentialist reasoning about money. Unlike the analysis of the composite Essentialist measure, there was a main effect for donor type in the American sample, $F(3,99)=6.35, p=.001, \eta_{\mathrm{p}}^{2}=0.16$. However, $t$-tests comparing similar-to-self baseline types to all other donor types indicated that similar-to-self types received significantly higher scores than different-from-self and negative donor types, again the opposite direction of that obtained in Study 1, and inconsistent with essentialist reasoning about money. There was no main effect of donor in the Indian sample, $F(3,84)=1.01, p=.39$.

Individual response patterns. Examination of the distribution of responses on the Essentialist measure further indicate that money donations were not essentialized. Distributions are presented in Table 9, again focusing on comparisons between similar-to-self and all other donor types (as was done in Studies 1 and 2). Binomial tests comparing the number of individuals reporting higher scores on non-similar-to-self types (a pattern indicative of essentialism) versus the number of individuals reporting lower scores on non-similar-to-self types (a pattern indicating lack of essentialism) were largely nonsignificant, $p \mathrm{~s}>.05$, with the single exception that significantly more Americans provided 
Table 9

Respondents providing each of three response patterns on essentialist measure in Study 3

\begin{tabular}{lccc}
\hline \multicolumn{1}{c}{ Response Pattern } & \multicolumn{2}{c}{ Donor Type } \\
\cline { 2 - 4 } & Different-From-Self & Positive & Negative \\
\hline American respondents & & 0.47 & 0.24 \\
Essentialism score lower than similar-to-self & 0.44 & 0.44 & 0.35 \\
Essentialism score equal to similar-to-self & 0.09 & 0.32 & 0.38 \\
Essentialism score higher than similar-to-self & & & 0.26 \\
Indian respondents & 0.38 & 0.28 & 0.38 \\
Essentialism score lower than similar-to-self & 0.28 & 0.34 & 0.21 \\
Essentialism score equal to similar-to-self & 0.34 & 0.38 & 0.41 \\
Essentialism score higher than similar-to-self & & & \\
\hline
\end{tabular}

lower scores for different-from-self types $(p<.01)$, which is opposite to the pattern obtained in Study 1 and inconsistent with essentialist reasoning on this control task.

\subsubsection{Non-Essentialist composite measure}

For Americans, there was a main effect of donor type on the Non-Essentialist measure, $F(3,99)=47.57, p<.001, \eta_{\mathrm{p}}^{2}=0.59$. Paired comparisons of similar-to-self (baseline) types against all other types showed that similar-to-self types were not differentiated from positive or different-from-self types but received significantly lower scores than negative types (Table 8). A similar pattern of results was seen in Indians; there was a main effect of donor type, $F(3,84)=14.43, p<.001, \eta_{\mathrm{p}}^{2}=0.34$, with paired comparisons indicating that similar-to-self types again were not differentiated from either positive or differentfrom-self types but received significantly lower scores than negative types (Table 8). These patterns are different from those obtained in Studies 1 and 2, in which similarto-self donor types were differentiated from all other donor types.

\subsubsection{Open-ended explanations}

A primary coder assessed respondents' explanations for essentialist predictions, as the main question motivating this study was whether respondents would expect money donations to be essentialized. An independent coder coded $20 \%$ of responses. Agreement was perfect $(\kappa=1.0)$. Only two open-ended responses showed evidence of essentialism (one from negative types, in an Indian respondent, and one from positive types, in an American respondent), accounting for $<1 \%$ of responses.

\subsubsection{Essentialism across countries and transplant types}

Data treatment. Compared with American respondents, Indian respondents gave overall higher values for all questions contributing to the composite essentialism and non-essentialism measures ( $p$ s $<.01)$; furthermore, scores specifically for baseline similar-to-self donors were also higher for Indian respondents ( $p s<.01)$, suggesting a non-equivalence in baseline scores between countries. This pattern is consistent with prior observations of 
overall higher agreement (irrespective of question type) on the part of Indian versus American online participants (Schulze, Seedorf, Geiger, Kaufmann, \& Schader, 2011) and prevented meaningful direct comparisons of scores across the two samples. Thus, to correct for this difference, we calculated scores for each participant reflecting the difference between the non-similar-to-self donor essentialism scores relative to the similar-to-self baseline essentialism scores. Note that these scores involve the essentialism composite measure only, and not any of the other measures (Liking or Non-Essentialist scores). These difference-from-baseline (DFB) scores were analyzed using a country (United States vs. India) $\times$ donor type (positive, different, negative) $\times$ transplant condition (bodily vs. non-bodily money control) ANOvA. (Species donor types were not included in this analysis, as no species donors were provided for the money control condition.)

Analysis. Notably, there was a main effect for transplant condition, $F(1,303)=9.97$, $p=.002, \eta_{\mathrm{p}}^{2}=0.03$, with DFB scores for bodily transplants higher $(M=.29, S D=.77)$ than for non-bodily money donations $(M=-.06, S D=.84)$; this is consistent with the idea that bodily transplants but not money would be essentialized. There was also a significant main effect for donor, $F(2,606)=13.88, p<.01, \eta_{\mathrm{p}}^{2}=0.04$. Tukey post-hoc comparison indicated that positive DFB scores $(M=0.33, S D=0.87)$ and negative DFB scores $(M=0.26, S D=1.03)$ were both significantly higher than different DFB scores $(M=0.08, S D=.83, p s<.01)$ but were not different from each other, $p=.14$. This result suggests that positive and negative donor types were essentialized more than different-from-self types (but recall from analyses performed for each country separately in Studies 1 and 2 that all three types were essentialized to some degree, evidenced by all three types receiving significantly higher scores than the similar-to-self baseline). There were no other main effects or interactions; most notably, country did not participate in any significant effects.

Finally, because cross-species donors were not included in the money control and thus were excluded from the prior analysis, we also compared the two countries in essentializing cross-species donors within the bodily transplant conditions alone. Again, the analyses involved the essentialism composite measure only. Indian respondents' DFB scores were significantly higher $(M=1.16, S D=1.57)$ than American respondents' $(M=0.68$, $S D=1.26), t(242)=2.56, p=.01$, Cohen's $d=0.34$.

\subsection{Discussion}

In Studies 1 and 2, we argued that people's endorsement of non-similar-to-self donors transferring characteristics to recipients through transplants reflected psychological essentialism. Study 3 was designed to rule out an alternative explanation for these findings, namely that respondents in Studies 1 and 2 may have been relying on a broader magical belief that any kind of transfer, not just internal bodily elements, might confer donors' traits on recipients. Study 3 served as a control to rule out this possibility by asking respondents to consider a money donation rather than a transplant. Both Americans and Indians did not expect money transfer to result in the recipient taking on characteristics 
of the donor, as indicated by scores on the Essentialism measure for non-similar-to-self types being largely equivalent to scores for similar-to-self types. Respondents instead endorsed causal-essentialist effects (transfer of personality/behavior and/or luck) only when considering transfer of internal body parts (Studies 1 and 2), not merely any kind of transfer (such as money). Overall, Study 3 strengthens our claim that Studies 1 and 2 were indicative of genuine essentialist thinking on the part of both Americans and Indians.

Analysis of DFB scores provides further evidence for the claim that bodily transplants are uniquely essentialized. Specifically, DFB scores were higher for bodily transplants than for non-bodily monetary transfer, consistent with the belief that bodily donations, but not monetary donations, may confer donors' characteristics to recipients. Thus, results from this analysis again indicate that in both countries, respondents differentiated the causal implications of receiving bodily versus non-bodily donations; the former was essentialized, whereas the latter was not. Notably, U.S.-India differences were typically not observed when examining DFB scores in the analysis of Studies 1, 2, and 3; the sole exception to this was that Indian respondents essentialized cross-species donors more than Americans.

\section{Study 4}

Results across the first three studies indicate that internal bodily elements, but not monetary donations, are seen as possessing a causal force that can be transferred via organ transplants. Although this strongly suggests that internal bodily elements are uniquely essentialized, monetary donations differ from bodily transplants in a number of ways that raise questions as to exactly which characteristics are necessary for something to be essentialized. Money is both external and acquired, typically on a temporary basis, and thus differs from a heart, blood, or DNA, each of which is an internal and inherent or biologically endowed part of someone's body. Must an element be both internal and biological for it to be seen as capable of transferring causal essence?

We designed Study 4 to investigate whether the internal versus external and biological versus acquired dimensions are relevant when making essentialist predictions. We compared individuals' responses to questions regarding three types of transfers: (a) a heart transplant, similar to that described in the prior studies, in which the donated element was thus both internal and biological; (b) a pacemaker exchange, in which the pacemaker from one individual was described as being put into the recipient's body and was thus an internal but acquired non-biological element; and (c) a skin graft, in which a portion of an individual's skin was described as being grafted onto the recipient and was thus an external but biological element.

As in Studies 1-3, we examined individuals in both the United States and India to compare patterns of essentializing along this dimension. Given that Studies 1-3 had already established that individuals essentialize the heart using similar-to-self donors as a baseline, we did not assess similar-to-self donors in Study 4. Instead, we expanded the 
range of possible donors within positive and negative types, with the plan of comparing essentializing across the three donor conditions (heart, transplant, and skin graft).

We also modified the survey structure relative to Studies 1-3 in two ways. First, we asked respondents about donations to themselves only, rather than to both themselves and their infants, because the infant versus self dimension did not participate in any effects of theoretical interest in the prior studies. Second, we shortened the survey by including only a Likert-scale liking item, an open-ended explanation/justification item, a single essentialism question, and a single non-essentialism question. The liking item and openended explanation request were identical to those in Studies 1-3 (Table 3). To provide respondents with a broader range of options for the essentialism and non-essentialism questions, we asked respondents for a percentage rather than a score on a 1-7 Likert scale. This change allowed for finer-grained analysis of the presence of these constructs. The question assessing essentialism was modeled after the Personality/Behavior item from Studies 1-3 and asked, "How possible is it that your personality/behavior might change to become more like that of this donor because of the graft? Please provide a value ranging from $0 \%$ to $100 \%$, where $0 \%$ indicates this is completely impossible and $100 \%$ indicates this is completely possible." The non-essentialism question was modeled after the Creeped Out/Contaminated item from Studies 1-3 and asked, "How 'creeped out' or 'contaminated' would you feel if you received your graft from this donor? Please provide a value ranging from $0 \%$ to $100 \%$, where $0 \%$ indicates you would not feel at all creeped out or contaminated and $100 \%$ indicates you would feel completely creeped out or contaminated."

\subsection{Method}

\subsubsection{Participants}

Respondents were obtained using Amazon's Mechanical Turk (American $n=136$, Indian $n=253$ ). ${ }^{2}$ We offered the survey to individuals in the United States (for the American sample) and India (for the Indian sample) and compensated each respondent \$1.49 for successful completion. Data from 14 additional American respondents and 91 additional Indian respondents were discarded due to incorrect answers to the attentioncheck questions. Additionally, we discarded data from eight surveys with duplicate IP addresses from the American sample, and from 31 surveys that had duplicate IP addresses from the Indian sample. Finally, respondents with average essentialism scores greater than three standard deviations outside their respective condition means (within each country) were removed from analysis. This excluded three American participants (one each from the heart, pacemaker, and skin graft conditions); no Indian respondents had outlying data.

\subsubsection{Survey materials}

Respondents read descriptions about one of three transfers: heart transplant (American $n=49$; Indian $n=82$ ), pacemaker exchange (American $n=47$, Indian $n=87$ ), or skin graft (American $n=40$, Indian $n=84$ ). Each respondent answered questions about a 
total of 12 donors, with six positive and six negative donors (Table 1). Text of the vignettes describing the transfers appears in Appendix A.

Respondents saw four questions about each donor. The liking item and open-ended explanation request appeared first, followed by the Personality/Behavior and Creeped Out/Contaminated items in counterbalanced order. Additionally, approximately half the participants saw one randomly determined order of donors, whereas the other half saw this order reversed. Order of Personality/Behavior and Creeped Out/Contaminated and donor order were crossed, and cell sizes within the four versions created by this crossing were approximately equal (American: heart $n=11-14$, pacemaker $n=11-13$, skin graft $n=9-11$; Indian: heart $n=18-23$, pacemaker $n=19-28$, skin graft $n=19-23$ ).

\subsection{Results}

For the sake of brevity, we focus solely on analyses of the Personality/Behavior and Creeped Out/Contaminated questions. For each question, a mixed-factorial 3 (transfer type: heart, pacemaker, skin graft) $\times 2$ (donor type: positive vs. negative) ANOVA was used, with transfer type as a between-subjects variable and donor type as a within-subjects variable. As in Studies 1-3, scores from Indian respondents on the essentialism item were substantially higher for the overall average relative to Americans $(p s<.01)$. Although this may genuinely reflect greater endorsement of essentialism, it is also possible that the difference reflects the same general tendency to provide higher values seen in Indian respondents relative to American respondents in Studies 1-3. This possibility prevented direct comparison between countries; thus, analyses for the two groups were performed separately.

American sample. For the Personality/Behavior item, there was a main effect of transfer type, indicative of differences in essentializing according to transfer condition, $F(2,133)=4.83, p=.01, \eta_{\mathrm{p}}^{2}=07$. Tukey post-hoc comparisons indicated that a heart transplant was judged more likely to transfer personality or behavior than either a pacemaker exchange or a skin graft, $p s<.03$; scores for pacemaker exchange and skin graft did not differ, however $(p>.05$; Table 10). Finally, the donor type $\times$ transfer condition interaction was not significant, $p>.05$. There was also a main effect of donor, $F(1$, $133)=5.93, p=.02, \eta_{\mathrm{p}}^{2}=0.04$, whereby respondents reported that positive donors would be more likely to transfer personality or behavior $(M=6.87 \%, S D=13.91)$ than negative donors $(M=3.83 \%, S D=7.93)$.

For the Creeped Out/Contaminated item, there was a main effect of donor, $F(1,133)=61.36, p<.001,=.32$, whereby respondents indicated they would feel more creeped out or contaminated by donations from negative donors $(M=28.03 \%$, $S D=27.86)$ than positive donors $(M=14.28 \%, S D=26.63)$. No other main effects or interactions were significant, $p s>.05$ (see Table 10 for means according to transfer type condition).

Indian sample. For the Personality/Behavior item, there was a main effect of donor, $F(1,250)=4.18, p=.04, \eta_{\mathrm{p}}^{2}=0.02$, whereby respondents reported that positive donors 
Table 10

Essentialist and Non-Essentialist scores by transfer type for Study 4

\begin{tabular}{|c|c|c|c|c|}
\hline \multirow[b]{3}{*}{ Transfer Type } & \multicolumn{4}{|c|}{ Measure } \\
\hline & \multicolumn{2}{|c|}{ Essentialist } & \multicolumn{2}{|c|}{ Non-Essentialist } \\
\hline & $M(\%)$ & $S D$ & $M(\%)$ & $S D$ \\
\hline \multicolumn{5}{|c|}{ American respondents } \\
\hline Heart & 8.44 & 13.55 & 18.38 & 19.40 \\
\hline Pacemaker & $3.01^{*}$ & 7.75 & 23.16 & 29.61 \\
\hline Graft & $2.95^{*}$ & 5.66 & 21.92 & 26.40 \\
\hline \multicolumn{5}{|c|}{ Indian respondents } \\
\hline Heart & 23.66 & 25.26 & 22.67 & 23.01 \\
\hline Pacemaker & 24.26 & 26.53 & 28.19 & 23.48 \\
\hline Graft & 24.42 & 21.80 & 29.05 & 22.96 \\
\hline
\end{tabular}

Note. ${ }^{*}$ Significantly lower than heart, $p<.03$.

would be more likely to transfer personality or behavior $(M=25.62 \%, S D=28.88)$ than negative donors $(M=22.61 \%, S D=25.32)$. No other main effects or interactions were significant, $p>.05$; most notably, this included no main effect for transfer type condition (see Table 10 for means), indicating no difference in endorsement of essentialism depending on the three types of transfers.

For the Creeped Out/Contaminated item, there was a main effect of donor, $F(1,250)=57.20, p<.001, \eta_{\mathrm{p}}^{2}=0.19$, whereby respondents indicated they would feel more creeped out or contaminated by donations from negative donors $(M=33.38 \%$, $S D=28.43)$ than positive donors $(M=19.99 \%, S D=25.77)$. No other main effects or interactions were significant, $p s>.05$ (see Table 10 for means according to transfer type condition).

\section{General discussion}

A significant body of work suggests that psychological essentialism contributes powerfully to the ways that we think about category structure, license and constrain inductive inference, and make judgments about the causes of outward behaviors and features of social, natural, and other kinds (Gelman, 2003; Medin, 1989; Medin \& Ortony, 1989). The current studies assessed whether essentialist beliefs also affect people's reasoning about bodies and transfers of internal bodily elements, in particular whether people believe that receiving a transplant can cause a recipient to take on characteristics of the donor. Psychological essentialism predicts this pattern of belief, because internal parts are taken to be suffused with essence. Thus, when an internal part is transferred from one individual to another, some of the donor's essence is also transferred and so will have a casual influence on the recipient. These studies constitute the first systematic, direct investigation of these essentialist beliefs in the general public. We found clear evidence for essentialist thinking: Respondents frequently endorsed the possibility of organ 
transplants or blood transfusions conferring a donor's characteristics, behaviors, or outward circumstances on the recipient.

Further, our data indicate not just the presence of essentialist thinking but also point to other aspects of its prevalence and nature. We found essentialist thinking in two distinct samples: Americans and Indians. The presence of essentialist thinking in two different countries supports the idea that essentialism is a bias that obtains across widely varying environmental inputs. Additionally, participants endorsed essentialist effects not just following a DNA transplant but also following a heart transplant or blood transfusion. Additionally, Indians (though not Americans) expected similar effects after transfer of other types of bodily elements that had long-term associations with the donor (pacemaker, skin graft). Notably, however, a control study (Study 3) indicated that causal effects were not deemed plausible when considering money donations, for either Indians or Americans. Taken together, these data indicate two additional important features of essentialism. First, causal essence is not promiscuously located in just anything that is associated with an individual (e.g., money). Second, causal essence is located in parts that biologists would argue are not, in fact, causally implicated in outward behaviors or qualities (such as the heart or blood). This latter finding is especially striking, because such a reasoning error indicates the operation of an essentialist bias independent of knowledge about the potential causal role of DNA and suggests that respondents often reject formal biological knowledge in favor of essentialism. (It is worth noting that responses were not universally indicative of essentialism; indeed, many individuals provided response patterns and openended explanations indicating explicit lack of belief in essentialist effects of transplants, suggesting that some people favored formal biological knowledge over essentialism. This is perhaps unsurprising; the explicit measures used in the current study were almost certainly conservative in their ability to detect essentialism.)

We suggest that it is people's representation of essence per se that is responsible for the effects. This is an important point, because the very existence of an essentialist bias has been questioned. As described in the Introduction, the minimalist approach argues for an alternative explanation for most of the findings in studies on essentialism thus far (Strevens, 2000). Specifically, Strevens argues that people do not represent an essence as a causal force in drawing inferences about an individual's features. Instead, according to the strongest interpretation of this position, people appeal directly to category membership as the basis on which to predict outward features. Our studies demonstrate, in contrast, that people who did not expect a transplant to result in a change in category membership (e.g., from human to pig) nevertheless endorsed the possibility that the transplant could change the recipient's category-typical behaviors to be more like those of the animal donor. Thus, category membership was not construed as necessary for outward features, because causal effects were deemed possible even in the absence of category change. These findings thus run counter to the predictions of unmediated minimalism. The findings reflect that people appeal to something more than just non-specific kindproperty links (K-laws) in drawing these sorts of inferences.

Our discussion has focused thus far on unmediated minimalism, but what of mediated minimalism, according to which people appeal to causal intermediaries in their reasoning? 
To account for our data, these causal intermediaries would have to have a range of characteristics: At the very least, they would have to be the sorts of things that can be transferred via organ transplants, and that exert causal influence on the recipient; they would have to be inherent; and they would have to be, at least for American adults, internal and biological. Once the nature of these causal intermediaries is constrained in this way, it becomes unclear how this view differs from psychological essentialism. ${ }^{3}$ Psychological essentialism is characterized as a "placeholder" notion (Medin \& Ortony, 1989), indicating that it does not attribute to people any specific beliefs about the nature of essence. Placeholder essentialism thus claims simply that people believe in an inherent, causal something-or-other, which is intimately connected with kind membership, but which is also separable from it. To suppose that belief in causal intermediaries with these characteristics is a distinct view from psychological essentialism is to saddle essentialism with more theoretical commitments than it in fact carries. If mediated minimalism is thus to be a distinct view, it would have to be far more carefully delineated in the literature than it has been thus far.

The current studies also speak to a related literature examining people's avoidance of contact with morally negative individuals and the items with which these individuals have associated, that is, magical contagion studies. A number of studies in this line of research have found extreme distaste for even indirect contact with morally negative entities (e.g., Nemeroff \& Rozin, 1994), findings that were recently extended by work indicating that people also dislike the idea of receiving organs from such individuals (Hood et al., 2011). The present studies add to this literature by showing the same distaste for organ transplants from negative donor types, those different from oneself, or different species. Importantly, our studies revealed specific reasons for this distaste: People are often alarmed by thoughts of essence-based changes in behavior or characteristics, as well as by feelings of contamination and social disapprobation.

Our data also provide insight into cultural differences and similarities in people's thinking. Striking similarities across the two countries were observed. Both Americans and Indians reported liking transplants from animals the least (replicating past studies suggesting particular distaste for animals as donors, for example, Coffman et al., 1998; Sanner, 2001a,b), followed by negative donor types, then different-from-self types, and finally positive types. Respondents from both countries also gave cross-species and negative donor types high scores on both the essentialist and non-essentialist measures, suggesting that reasons for distaste for dissimilar or negative entities are shared across these two cultural contexts.

On the other hand, cross-country differences were also revealed. First, Indian respondents appeared to essentialize cross-species donors more than Americans, as indicated by a greater difference between scores for these types and baseline similar-to-self types. Second, Indian respondents also appeared to essentialize more types of transfers than Americans; specifically, they did not differentiate essentialist predictions for heart, pacemaker, or skin graft transfer. It may be that Americans and Indians possess distinct concepts of essence, with Indians treating a broader range of elements as having causal properties. Alternatively, American and Indian representations of essence may be 
fundamentally similar, but Indians may be more likely to expect internal essences to be transferred to objects or parts as a result of extensive direct contact with the individual (see Nemeroff \& Rozin, 1994, for discussion of this latter form of essentialism). Further research is needed to determine which interpretation is valid, as well as the factors that contribute to people's tendency to extend essentialist effects to non-internal or nonbiological elements.

The present investigation still leaves open a number of other important issues. For example, we found evidence for essentialist thinking about a wide range of social categories. How exactly are these essentialist beliefs to be modeled? Haslam and colleagues have proposed that, in the social domain, essentialism includes two highly dissociable (though not mutually exclusive) dimensions: naturalness and entitativity (Haslam et al., 2000). They argue that some essentialized social groups tend to be conceived of as more natural or biologically based (e.g., race, gender), whereas other essentialized social groups tend to be conceived of as more entitative, with members highly similar to one another (e.g., homosexuals). One might predict that it is only categories deemed biologically based that would also be considered viable candidates for transferring bodily causal essence, yet our data suggest that essentialism is influential for more than just categories considered natural or biologically based such as gender or species. Results from our study may thus be seen as indicating the existence of pseudo-biological conceptualizations of a wide range of social categories, a notable finding that warrants further investigation. Questions for future research include the following: What is the causal route by which people expect essences from various categories to take their effects? and Does this differ depending on how natural a category is considered?

Our data also point to potential questions regarding the distinction between categorybased essence versus individual-based essence. Here, we argue that transplants from various social and animal categories may be predicted to transfer category-typical attributes, including personality and behavior. Personality and behavior, however, are also arguably in equal measure components of one's individual identity; how might psychological essentialism function when considering what causal forces underlie unique individuals? A number of researchers have noted potential parallels as well as areas of disconnect between essentializing individuals versus categories (Blok, Newman, \& Rips, 2005; Gelman \& Hirschfeld, 1999; Gutheil, Gelman, Klein, Michos, \& Kelaita, 2008; Gutheil \& Rosengren, 1996; Leslie, in press b; Rips, Blok, \& Newman, 2006), yet the precise relationship between the two has not been thoroughly established. Future work within the domain of transplants may contribute to resolving this; for instance, is a transfer of essence via a transplant expected to compromise or alter the identity of either the donor or the recipient? If so, does this draw on the same essentialist intuitions that were revealed in the current study?

Also unanswered is how essentialist beliefs about bodies develop. A large body of literature indicates the presence of essentialist beliefs from an early age, and a number of studies indicate that children expect essence to be located internally (Gelman, 2003). Might such essentialist thinking be observed when asking children to consider the effects of transplants (e.g., by asking children to consider the results of trading a heart with a 
pig)? Studies by Johnson (1990) as well as Gottfried, Gelman, and Schultz (1999) provide intriguing initial evidence that bears on the question of how children reason about transplants. In both sets of studies, children were asked to consider the outcomes of trading brains with various individuals. Children showed developmental progression in the ability to recognize how the brain functions to contain thoughts and memories. Johnson additionally compared children's responses to brain transplant scenarios and other body parts (heart and mouth). Although children by early elementary school were likely to expect the traded brain to be the most important factor in determining the recipient's later behavior and thinking, they also showed some evidence of expecting the other transplants to result in causal changes as well; for instance, the majority of children expected a heart from a mean person would reduce the recipient's kindness. Future work can extend these findings by examining precisely what kinds of donors (e.g., members of a wide range of social groups as well as animals), body parts (e.g., heart vs. blood), and traits (kindness, intelligence, etc.) might be essentialized in the contexts of transplant scenarios.

Finally, our studies may shed some light on the concerns that real-life transplant patients may have before and after their procedures. Specifically, our results point to the possibility that patients may entertain non-scientifically based worries; despite the absence of medical evidence to suggest that organ transplants or blood transfusions can cause changes in personality or life circumstances, our respondents still considered such outcomes possible. Belief in such possibilities, we suggest, is rooted in essentialism-a deep and pervasive cognitive bias.

\section{Acknowledgments}

This research was supported by National Science Foundation grant 059394 to Gelman. We gratefully acknowledge the research assistance of Elizabeth Anastasia and Jocelyn Kuhn.

\section{Notes}

1. The term "non-essentialist" does not imply denial of essentialism, but rather it is used to describe beliefs that are not indicative of essentialism.

2. Approximately, twice as many Indian respondents were obtained due to higher variability in their responses. Standard deviations within each transfer type condition were approximately two to three times higher in the Indian versus American sample.

3. To clarify, philosophical discussions of essence often invoke something more elaborate and specific than what is implied by psychological essentialism. For example, when Kripke (1980) or Putnam (1975) speak of natural kinds having essences, they mean to claim in part that there is a particular property, possession of which is both necessary and sufficient for being a member of the kind. Thus, being $\mathrm{H}_{2} \mathrm{O}$ is often claimed to be the essence of water, in the sense that all and only things that are 
$\mathrm{H}_{2} \mathrm{O}$ count as water-this is just what it is, metaphysically or scientifically speaking, for something to be water. For additional discussion of different kinds of essentialism, see Gelman, 2003; Chapter 1 and Leslie, in press b.

\section{References}

Ahn, W., Kalish, C., Gelman, S. A., Medin, D. L., Luhmann, C., Atran, S., Coley, J. D., \& Shafto, P. (2001). Why essences are essential in the psychology of concepts. Cognition, 82, 59-69.

Ahn, W., Kim, N. S., Lassaline, M. E., \& Dennis, M. J. (2000). Causal status as a determinant of feature centrality. Cognitive Psychology, 41, 361-416.

Allport, G. W. (1954). The nature of prejudice. Reading, MA: Addison-Wesley.

Astuti, R., Solomon, G., \& Carey, S. (2004). Constraints on conceptual development: A case study of the acquisition of folkbiological and folksociological knowledge in Madagascar. Monographs of the Society for Research in Child Development, 69, vii-135.

Atran, S. (1990). Cognitive foundations of natural history. Cambridge, UK: Cambridge University Press.

Atran, S. (1998). Folk biology and the anthropology of science: Cognitive universals and cultural particulars. Behavioral and Brain Sciences, 21, 547-569.

Atran, S., \& Medin, D. (2008). The native mind and the cultural construction of nature. Cambridge, MA: MIT Press.

Basch, S. H. (1973). The intrapsychic integration of a new organ: A clinical study of kidney transplantation. Psychoanalytic Quarterly, 42, 364-384.

Bastian, B., \& Haslam, N. (2006). Psychological essentialism and stereotype endorsement. Journal of Experimental Social Psychology, 42, 228-235.

Belk, R. W. (1990). Me and thee versus mine and thine: How perceptions of the body influence organ donation and transplantation. In J. Shanteau \& R. J. Harris (Eds.), Organ donation and transplantation: Psychological and behavioral factors (pp. 139-149). Washington, DC: American Psychological Association.

Birnbaum, D., Deeb, I., Segall, G., Ben-Eliyahu, A., \& Diesendruck, G. (2010). The development of social essentialism: The case of Israeli children's inferences about Jews and Arabs. Child Development, 81, 757777.

Blok, S. V., Newman, G. E., \& Rips, L. J. (2005). Individuals and their concepts. In W. K. Ahn, R. L. Goldstone, B. C. Love, A. B. Markman, \& P. Wolff (Eds.), Categorization inside and outside the laboratory (pp. 127-149). Washington DC: American Psychological Association.

Callan, M. J., Ellard, J. H., \& Nicol, J. E. (2006). The belief in a just world and immanent justice reasoning in adults. Personality and Social Psychology Bulletin, 32, 1646-1658.

Coffman, K. L., Sher, L., Hoffman, A., Rojter, S., Folk, P., Cramer, D., Vierling, J., Villamel, F., Podesta, L., Demetriou, A., \& Makowka, L. (1998). Survey results on transplant patients' attitudes on xenografting. Psychosomatics, 39, 379-383.

Conan Doyle, A. (1923). The adventure of the creeping man. In A. Conan Doyle, The case-book of Sherlock Holmes. 1927; republished 2001, Cornwall, UK: House of Stratus.

Dewar, K., \& Xu, F. (2009). Do early nouns refer to kinds or distinct shapes? Psychological Science, 20, 252-257.

Diesendruck, G., \& Haber, L. (2009). God's categories: The effect of religiosity on children's teleological and essentialist beliefs about categories. Cognition, 110, 100-114.

Diesendruck, G., \& haLevi, H. (2006). The role of language, appearance, and culture in children's social category-based induction. Child Development, 77, 539-553.

Feeley, T. H., \& Moon, S. (2009). A meta-analytic review of communication campaigns to promote organ donation. Communication Reports, 22, 63-73. 
Frazier, B. N., Gelman, S. A., Wilson, A., \& Hood, B. (2009). Picasso paintings, moon rocks, and handwritten Beatles lyrics: Adults' evaluations of authentic objects. Journal of Cognition and Culture, 9, 1-14.

Gelman, S. A. (2003). The essential child: Origins of essentialism in everyday thought. New York: Oxford University Press.

Gelman, S. A., \& Coley, J. D. (1990). The importance of knowing a dodo is a bird: Categories and inferences in 2-year-old children. Developmental Psychology, 26, 796-804.

Gelman, S. A., \& Gottfried, G. D. (1996). Causal explanations of animate and inanimate motion. Child Development, 67, 1970-1987.

Gelman, S. A., \& Heyman, G. D. (1999). Carrot-eaters and creature-believers: The effects of lexicalization on children's inferences about social categories. Psychological Science, 10, 489-493.

Gelman, S. A., \& Hirschfeld, L. A. (1999). How biological is essentialism? In D. L. Medin \& S. Atran (Eds.), Folkbiology (pp. 403-446). Cambridge, MA: MIT Press.

Gelman, S. A., \& Kremer, K. E. (1991). Understanding natural cause: Children's explanations of how objects and their properties originate. Child Development, 62, 396-414.

Gelman, S. A., \& Markman, E. M. (1986). Categories and induction in young children. Cognition, 23, $183-209$.

Gelman, S. A., \& Markman, E. M. (1987). Young children's inductions from natural kinds: The role of categories and appearances. Child Development, 58, 1532-1541.

Gelman, S. A., Taylor, M. G., \& Nguyen, S. (2004). Mother-child conversations about gender: Understanding the acquisition of essentialist beliefs. Monographs of the Society for Research in Child Development, 69, vii-126.

Gelman, S. A., \& Wellman, H. M. (1991). Insides and essences: Early understandings of the nonobvious. Cognition, 38, 213-244.

Gil-White, F. J. (2001). Are ethnic groups biological "species" to the human brain? Essentialism in our cognition of some social categories. Current Anthropology, 42, 515-554.

Gottfried, G. M., \& Gelman, S. A. (2005). Developing domain-specific causal-explanatory frameworks: The role of insides and immanence. Cognitive Development, 20, 137-158.

Gottfried, G. M., Gelman, S. A., \& Schultz, J. (1999). Children's understanding of the brain: From early essentialism to biological theory. Cognitive Development, 14, 147-174.

Graham, S. A., Kilbreath, C. S., \& Welder, A. N. (2004). Thirteen-month-olds rely on shared labels and shape similarity for inductive inferences. Child Development, 75, 409-427.

Gutheil, G., Gelman, S. A., Klein, E., Michos, K., \& Kelaita, K. (2008). Preschoolers' use of spatiotemporal history, appearance, and proper name in determining individual identity. Cognition, 107, 366-380.

Gutheil, G., \& Rosengren, K. S. (1996). A rose by any other name: Preschoolers' understanding of individual identity across name and appearance changes. British Journal of Developmental Psychology, 14, 477-498.

Haslam, N., Bastian, B., Bain, P., \& Kashima, Y. (2006). Psychological essentialism, implicit theories, and intergroup relations. Group Processes and Intergroup Relations, 9, 63-76.

Haslam, N., Rothschild, L., \& Ernst, D. (2000). Essentialist beliefs about social categories. British Journal of Social Psychology, 39, 113-127.

Hayward, C., \& Madill, A. (2003). The meanings of organ donation: Muslims of Pakistani origin and white English nationals living in North England. Social Science and Medicine, 57, 389-401.

Hejmadi, A., Rozin, P., \& Siegal, M. (2004). Once in contact, always in contact: Contagious essence and conceptions of purification in American and Hindu Indian children. Developmental Psychology, 40, $467-476$.

Hirschfeld, L. A. (1996). Race and making: Cognition, culture, and the child's construction of human kinds. Cambridge, MA: MIT Press.

Hirschfeld, L. A. (2001). On a folk theory of society: Children, evolution, and mental representations of social groups. Personality and Social Psychology Review, 5, 107-117.

Hood, B. M., Gjersoe, N. L., Donnelly, K., Byers, A., \& Itajkura, S. (2011). Moral contagion attitudes towards potential organ transplants in British and Japanese adults. Journal of Culture and Cognition, 11, 269-286. 
Inspector, I., Kutz, Y., \& David, D. (2004). Another person's heart: Magical and rational thinking in the psychological adaptation to heart transplantation. The Israeli Journal of Psychiatry and Related Sciences, $41,161-173$.

Jha, V. (2004). Paid transplants in India: The grim reality. Nephrology Dialysis Transplantation, 19, 541-543.

Johnson, C. N. (1990). If you had my brain, where would I be? Children's understanding of the brain and identity. Child Development, 61, 962-972.

Johnson, C. N., \& Jacobs, M. G. (2001, April). Enchanted objects: How positive connections transform thinking about the very nature of things. Poster presented at the Society for Research in Child Development, Minneapolis, MN.

Kalbag, S. (2008, February 2). India's kidney racket story goes global. Hindustan Times. Available at: http:// www.hindustantimes.com/India-s-kidney-racket-story-goes-global/Article1-273439.aspx Accessed March 1, 2012

Keil, F. C. (1989). Concepts, kinds, and cognitive development. Cambridge, MA: MIT Press.

Keller, J. (2005). In genes we trust: The biological component of psychological essentialism and its relationship to mechanisms of motivated social cognition. Journal of Personality and Social Psychology, 88, 686-702.

Kinnear, P. R., \& Gray, C. D. (2004). SPSS 12 made simple. New York: Psychology Press.

Kripke, S. (1980). Naming and necessity. Cambridge, MA: Harvard University Press.

Lederer, S. E. (2008). Flesh and blood: Organ transplantation and blood transfusion in 20th century America. New York: Oxford University Press.

Leslie, S.-J. (in press a). The original sin of cognition: Fear, prejudice, and generalization. The Journal of Philosophy.

Leslie, S.-J. (in press b). Essence and natural kinds: When science meets preschooler intuition. Oxford Studies in Epistemology, 4.

Mahalingam, R. (2003). Essentialism and beliefs about gender among Aravanis, the "not-men" of Tamilnadu. Sex Roles, 49, 489-496.

Mahalingam, R., Haritatos, J., \& Jackson, B. (2007). Essentialism and the cultural psychology of gender in extreme son preference communities in India. American Journal of Orthopsychiatry, 77, 598-609.

Mayr, E. (1982). The growth of biological thought. Cambridge, MA: Harvard University Press.

McIntosh, J. (2009). The edge of Islam: Power, personhood, and ethnoreligious boundaries on the Kenya coast. Durham, NC: Duke University Press.

McLean, S. A. M., \& Williamson, L. (2005). Xenotransplantation: Law and ethics. Aldershot, England: Ashgate Publishing Ltd..

Medin, D. L. (1989). Concepts and conceptual structure. American Psychologist, 44, 1469-1481.

Medin, D. L., \& Ortony, A. (1989). Psychological essentialism. In S. Vosniadou \& A. Ortony (Eds.), Similarity and analogical reasoning (pp. 179-196). New York: Cambridge University Press.

Narula, S. (1999). Broken people: Caste violence against India's "Untouchables." Human Rights Watch.

Nemeroff, C., \& Rozin, P. (1989). "You are what you eat": Applying the demand-free "impressions" technique to an unacknowledged belief. Ethos, 17, 50-69.

Nemeroff, C., \& Rozin, P. (1994). The contagion concept in adult thinking in the United States: Transmission of germs and interpersonal influence. Ethos, 22, 158-186.

Newman, G. E., Diesendruck, G., \& Bloom, P. (2011). Celebrity contagion and the value of objects. Journal of Consumer Research, 38, 215-228.

Newman, G. E., \& Keil, F. C. (2008). Where's the essence? Developmental shifts in children's beliefs about internal features. Child Development, 79, 1344-1356.

Olivelle, P. (1995). Food in India. Journal of Indian Philosophy, 23, 367-380.

Olson, K. R., Banaji, M. R., Dweck, C. S., \& Spelke, E. S. (2006). Children's bias against lucky vs. unlucky people and their social groups. Psychological Science, 17, 845-846.

Panjabi, R. K. L. (2011). The sum of a human's parts: Global organ trafficking in the twenty-first century. Pace Environmental Law Review, 28, 1-144. 
Prentice, D. A., \& Miller, D. T. (2007). Psychological essentialism of human categories. Current Directions in Psychological Science, 16, 202-206.

Putnam, H. (1975). The meaning of 'meaning'. In H. Putnam (Ed.), Mind, language, and reality (pp. 215271). Cambridge, UK: Cambridge University Press.

Rhodes, M., \& Gelman, S. A. (2009). A developmental examination of the conceptual structure of animal, artifact, and human social categories across two cultural contexts. Cognitive Psychology, 59, 244-274.

Rips, L. J., Blok, S. V., \& Newman, G. E. (2006). Tracing the identity of objects. Psychological Review, $113,1-30$.

Ross, J., Irani, L., Silberman, M. S., Zaldivar, A., \& Tomlinson, B. (2010). Who are the Crowdworkers? Shifting demographics in Mechanical Turk. In Extended abstracts of CHI 2010 (ACM Conference on Human Factors in Computing Systems) (pp. 2863-2872).

Rothbart, M., \& Taylor, M. (1992). Category labels and social reality: Do we view social categories as natural kinds? In G. Semin \& K. Fiedler (Eds.), Language, interaction and social cognition (pp. 11-36). London: Sage.

Rozin, P., Markwith, M., \& McCauley, C. (1994). Sensitivity to indirect contacts with other persons: AIDS aversion as a composite of aversion to strangers, infection, moral taint, and misfortune. Journal of Abnormal Psychology, 103, 495-505.

Rozin, P., Millman, L., \& Nemeroff, C. (1986). Operation of the laws of sympathetic magic in disgust and other domains. Journal of Personality and Social Psychology, 50, 703-712.

Salahudeen, A. K., Woods, H. F., Pingle, A., Suleyman, M. N., Shakuntala, K., Nandakumar, M., \& Daar, T. M. (1990). High mortality among recipients of bought living-unrelated donor kidneys. Lancet, 336, 725 728.

Sanner, M. A. (2001a). Exchanging spare parts or becoming a new person? People's attitudes toward receiving and donating organs. Social Science and Medicine, 52, 1491-1499.

Sanner, M. A. (2001b). People's feelings and beliefs about receiving transplants of different origins-questions of life and death, identity, and nature's border. Clinical Transplantation, 15, 19-27.

Schulze, T., Seedorf, S., Geiger, D., Kaufmann, N., \& Schader, M. (2011, June). Exploring task properties in crowdsourcing: An empirical study on Mechanical Turk. In Proceedings of the 19th European Conference on Information Systems (ECIS), Paper 122.

Smiler, A., \& Gelman, S. A. (2008). Determinants of gender essentialism in college students. Sex Roles, 58, 864-874.

Strevens, M. (2000). The essentialist aspect of naive theories. Cognition, 74, 149-175.

Strevens, M. (2001). Only causation matters: Reply to Ahn et al.. Cognition, 82, 71-76.

Sylvia, C. (with Novak, W.) (1997). A change of heart: A memoir. New York: Time Warner.

Taylor, M. G., Rhodes, M., \& Gelman, S. A. (2009). Boys will be boys; cows will be cows: Children's essentialist reasoning about gender categories and animal species. Child Development, 80, 461-481.

Waxman, S. R., Medin, D. L., \& Ross, N. (2007). Folkbiological reasoning from a cross-cultural developmental perspective: Early essentialist notions are shaped by cultural beliefs. Developmental Psychology, 43, 294-308.

\section{Supporting Information}

Additional Supporting Information may be found in the online version of this article:

Appendix S1. Text of vignettes for each transplant type and recipient. 